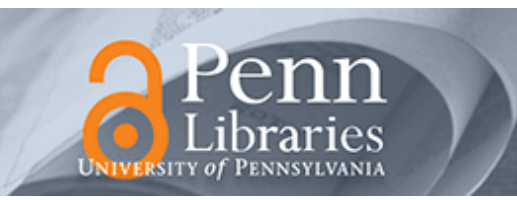

University of Pennsylvania

ScholarlyCommons

\title{
Effect Pathways of Informal Family Separation on Children's Outcomes: Paternal Labor Migration and Long-term Educational Attainment of Left-Behind Children in Rural China
}

\author{
Wensong Shen \\ The Chinese University of Hong Kong, wensongshen@cuhk.edu.hk \\ Li-Chung $\mathrm{Hu}$ \\ National Chengchi University, Ichu@nccu.edu.tw \\ Emily Hannum \\ University of Pennsylvania, hannumem@soc.upenn.edu
}

Follow this and additional works at: https://repository.upenn.edu/education_inequality_workshop

Part of the Asian Studies Commons, Family, Life Course, and Society Commons, Inequality and Stratification Commons, and the International and Comparative Education Commons

\section{Recommended Citation}

Shen, Wensong, Li-Chung Hu, and Emily Hannum. 2021. "Effect Pathways of Informal Family Separation on Children's Outcomes: Paternal Labor Migration and Long-term Educational Attainment of Left-Behind Children in Rural China." Penn Education and Inequality Working Papers, \#8. https://repository.upenn.edu/ education_inequality_workshop/8

This working paper was published in a journal:

Shen, Wensong, Li-Chung Hu, and Emily Hannum. 2021. "Effect Pathways of Informal Family Separation on Children's Outcomes: Paternal Labor Migration and Long-Term Educational Attainment of Left-Behind Children in Rural China." Social Science Research 97:102576. PMCID: PMC8442607. https://doi.org/10.1016/ j.ssresearch.2021.102576.

This paper is posted at ScholarlyCommons. https://repository.upenn.edu/education_inequality_workshop/8 For more information, please contact repository@pobox.upenn.edu. 


\title{
Effect Pathways of Informal Family Separation on Children's Outcomes: Paternal Labor Migration and Long-term Educational Attainment of Left-Behind Children in Rural China
}

\begin{abstract}
Informal family separation due to parental labor migration is an increasingly common experience in the lives of children in many countries. This paper proposes a framework and method for analyzing "effect pathways" by which parental labor migration might affect children's outcomes. The framework incorporates home-environment and child-development mechanisms and is adapted from migration, sociology of education and child development literatures. We test these pathways using data on father absence and long-term educational outcomes for girls and boys in China. We apply structural equation models with inverse probability of treatment weighting to data from a 15-year longitudinal survey of 2,000 children. Significantly, fathers' migration has distinct implications for different effect pathways. It is associated most significantly with reduced human capital at home, which has the largest detrimental effect on children's educational attainment, among those studied. At the same time, father absence is associated with better family economic capital, which partially buffers the negative implications of father absence. Overall, father absence corresponds to a reduction of 0.342 years on average in children's educational attainment, but the reduction is larger for boys than for girls. For boys and girls, the reduced availability of literate adults in the household linked to father absence is an important effect pathway. For girls, this detrimental effect is partially offset by a positive income effect, but for boys, the offset effect is trivial.
\end{abstract}

\section{Keywords}

family separation, educational attainment, China, left-behind children, paternal labor migration, father absence

Disciplines

Asian Studies | Education | Family, Life Course, and Society | Inequality and Stratification | International and Comparative Education

\section{Comments}

This working paper was published in a journal:

Shen, Wensong, Li-Chung Hu, and Emily Hannum. 2021. "Effect Pathways of Informal Family Separation on Children's Outcomes: Paternal Labor Migration and Long-Term Educational Attainment of Left-Behind Children in Rural China." Social Science Research 97:102576. PMCID: PMC8442607. https://doi.org/ 10.1016/j.ssresearch.2021.102576. 


\title{
Effect Pathways of Informal Family Separation on Children's Outcomes: Paternal Labor Migration and Long-term Educational Attainment of Left-behind Children in Rural China
}

\author{
Wensong Shen, Li-Chung Hu, and Emily Hannum
}

\begin{abstract}
Informal family separation due to parental labor migration is an increasingly common experience in the lives of children in many countries. This paper proposes a framework and method for analyzing "effect pathways" by which parental labor migration might affect children's outcomes. The framework incorporates home-environment and child-development mechanisms and is adapted from migration, sociology of education and child development literatures. We test these pathways using data on father absence and long-term educational outcomes for girls and boys in China. We apply structural equation models with inverse probability of treatment weighting to data from a 15-year longitudinal survey of 2,000 children. Significantly, fathers' migration has distinct implications for different effect pathways. It is associated most significantly with reduced human capital at home, which has the largest detrimental effect on children's educational attainment, among those studied. At the same time, father absence is associated with better family economic capital, which partially buffers the negative implications of father absence. Overall, father absence corresponds to a reduction of 0.342 years on average in children's educational attainment, but the reduction is larger for boys than for girls. For boys and girls, the reduced availability of literate adults in the household linked to father absence is an important effect pathway. For girls, this detrimental effect is partially offset by a positive income effect, but for boys, the offset effect is trivial.
\end{abstract}




\section{Introduction}

Informal family separation ${ }^{1}$ due to parental labor migration is an increasingly common experience in the lives of children in many countries. Globally, it is estimated that hundreds of millions of children are left behind due to parental migration or absence, ${ }^{2}$ and this number continues to grow (Fellmeth et al. 2018). The immense scale of the left-behind phenomenon has prompted intense academic scrutiny, with numerous scholars investigating the problems faced by left-behind children. Yet, findings are surprisingly mixed regarding how these children fare (Wen et al. 2015; Liang 2016; Adams, Cuecuecha, and Page 2008; Arguillas and Williams 2010). A critical reason for these mixed findings is that parental migration, in principle, may carry distinct implications in the different domains of the home environment that contextualize children's education and development. For example, migration may lead to greater material resources in the household through remittances - resources that can ensure a child's access to education (Carling, Menjívar, and Schmalzbauer 2012, 193) - but lower "social capital" if parental supervision or assistance with homework decreases. However, we know little about the mechanisms linking parental migration to outcomes, because most of the literature investigates gaps in outcomes associated with parental absence, without specifying pathways of influence.

In this paper, using the case of China, we propose an approach for investigating the long-term educational implications of parental absence for children, with an emphasis on "effect pathways" or mechanisms linking parental absence in childhood to long-term educational outcomes. We capitalize on availability of information about father absence in a 15-year longitudinal data collection project that followed rural children and their families from 100 villages in Northwest China. We combine Liang's "resource generation model" and "family disruption model" of parental migration (Liang 2016) with a framework for analyzing children's home environments grounded in human, social, and cultural capital theories in sociology of education. We do this by identifying elements of children's home environments that are likely to be affected by parental migration and that fit within established theoretical frameworks for analyzing educational reproduction and mobility. We also investigate the potential implications of parental absence and home environment effects via children's own developmental outcomes at the time of parental absence - academic performance and behavioral problems. Finally, we address the possibility that father absence has different implications for boys' and girls' educational attainment.

To address concerns about selectivity of labor migration, we apply structural equation models with inverse probability of treatment weighting, in which father absence from the home due to migration is defined as the treatment and all other living arrangements form the control group. We operationalize "effect pathways" of parental absence as pathways through which parental absence has a significant effect on a mediator that, in turn, has a significant effect on long-term educational outcomes. In this way, we are able to consider both positive and negative

\footnotetext{
${ }^{1}$ We use the term "informal family separation" to contrast parental absence due to labor migration with formally-recognized forms of family separation tied to parents' marital status (formally separated, divorced, unmarried, or widowed).

${ }^{2}$ Parental absence refers to the status of parent(s) being absent from home due to migration. Children who move with their migrant parents are not included in this paper. In this sense, we use parental absence and parental migration interchangeably, both of which mean children are left behind at home by their migrant parent(s).
} 
implications of absence via different mediation pathways, and we are able to quantify the size of the total effect of absence attributable to each effect pathway.

\section{Theoretical Framework and Research Questions}

Many scholars have examined the educational and developmental consequences of parental migration or absence for children, but findings are mixed. For example, some scholars argue that left-behind children benefit from increased family income, which leads to better educational outcomes (e.g., Hadi 1999; Jones and Kittisuksathit 2003). Other studies find that the changes in family structure and the absence of parental involvement due to parental migration have negative implications for children's educational outcomes (e.g., Meng and Yamauchi 2017; Jampaklay 2006). A study analyzing the Mexican Family Life Survey and the Indonesian Family Life Survey finds that international migration of parents and, in Mexico, some forms of domestic parental migration, are negatively associated with children's grade attainment (Lu 2014). Studies in some settings suggest that paternal migration does not play a major role in determining children's educational outcomes (e.g., Antman 2012; Ren and Treiman 2016; Xu and Xie 2015; Lu 2012). For example, a recent analysis of the China Family Panel Studies finds that the gap in Chinese adolescents' development and education is not directly related to the number of parents they grow up with but the rural or urban environment in which they grow up (Yeung and $\mathrm{Gu}$ 2016). The inconsistent empirical findings about parental migration and children's outcomes may be explained by a variety of differences across studies, such as the origin and destination of migration, the age and gender of left-behind children, the gender of migrant parent, and the time of migration, among others. But in explaining positive or negative results, authors often resort implicitly or explicitly to two competing theoretical frameworks: the resource generation model and the family disruption model (Liang 2016).

The resource generation model posits that parental migration has positive effects on home environment, brought about by improved economic resources or economic capital. Economic capital refers to resources that are "immediately and directly convertible into money and may be institutionalized in the form of property rights" (Bourdieu 1986, 16). There is good reason to believe, in some contexts, that this might be the case. For example, existing literature in China estimates that remittances constitute about $20 \%$ of total incomes in migrant households (Fan 2008). One study in South Africa shows that remittances from migrant parents substantially increase children's school attendance and household educational spending, which ameliorates educational inequality among children (Lu and Treiman 2011).

The family disruption model, in contrast, posits that parental absence in childhood may reduce both the quantity and quality of social, emotional, and intellectual stimuli for children, which ultimately leads to adverse child developmental outcomes (Parreñas 2005; Dreby 2010). One key mechanism could be described as human capital loss in the household. According to Coleman (1988), human capital refers to "skills and capabilities that make them [persons] able to act in new ways" (S100), which is "approximately measured by parents' education and provides the potential for a cognitive environment for the child that aids learning" (S109). ${ }^{3}$ In the language of Coleman, parental migration implies the loss of parental human capital for left-behind children

\footnotetext{
${ }^{3}$ Parental education has been closely associated with investments in children and with children's educational outcomes in rural China (Brown 2006; Zhao and Glewwe 2010).
} 
during the period of parental absence. In poor rural regions, the absent parent or parents may be the most educated among adults in the household, and their temporary loss may leave children without a source of mentorship or advocacy when educational challenges arise. A recent study in China based on national data finds that when parents out-migrate, the alternative primary caregivers have lower education, which explains about $21 \%$ of left-behind children's disadvantage in literacy skills (Lu, Yeung, and Treiman 2020). However, the extent to which parental human capital loss is linked to left-behind children's long-term educational outcomes remains unclear.

Related to the human capital loss mechanism, social capital is a critical domain of home environment in the sociology of education literature that could be affected by parental absence. Nationally, there are striking socioeconomic differences in children's access to some forms of family social capital, including parental supervision and family activities, and a part of this pattern might be attributed to the much higher reported rate of living apart from parents among children in socioeconomically disadvantaged families (Young and Hannum 2018). Parental migration is associated, in some studies, with a lack of parental involvement, schoolwork supervision, and emotional support for left-behind children (Hannum et al. 2018; Liang 2016). There is also evidence supporting contradictory results. For example, some research suggests that for families with only one parent absent, the stay-at-home primary caregiver (usually the mother) may tend to compensate with higher levels of parental warmth or support toward children (Xinyin Chen et al. 2019).

Cultural capital is another dimension of household context that is crucial for children's educational outcomes (De Graaf, De Graaf, and Kraaykamp 2000; DiMaggio 1982; Lareau and Weininger 2003; Bourdieu 1986). Scholars have proposed diverse conceptions of cultural capital in relation to education. For example, Davies and Rizk $(2017,1)$ trace three distinct lineages of work on cultural capital and schooling: the "DiMaggio tradition," which uses survey methods to conceive cultural capital as resources that shape student outcomes; the "Lareau tradition," which uses qualitative observations to interpret cultural capital as family strategies that align with schools' institutional rewards; and the "Collins tradition," which offers a microoriented conception of cultural capital as stocks of meanings that facilitate ritual interactions. In survey-based work that treats cultural capital as cultural resources, common operational definitions include the number of books and magazines, book-reading behaviors, extracurricular activities, and participation in arts-related activities, depending on social contexts and research topics (DiMaggio and Mukhtar 2004; Lareau and Horvat 1999). One study shows that there are substantial social class differences in book-reading behaviors among children in urban China (Wang et al. 2006). Another study suggests sharp socioeconomic gradients in reading with children and children's access to cultural institutions (Young and Hannum 2018). However, the role played by cultural resources as a mechanism linking parental absence to educational outcomes in rural areas has not been studied.

Parental absence may be associated with differences not only in home environment, but also in children's immediate, individual developmental outcomes. A large body of literature has examined the deleterious effects of parental absence on left-behind children's emotional and behavioral problems (F. Fan et al. 2010; Qin and Albin 2010; Adhikari et al. 2014). For instance, a cross-country comparative study in Africa finds that parental migration is negatively associated 
with left-behind children's psychological well-being (Mazzucato et al. 2015). A review of the literature on father absence in the United States, which is admittedly tied more to non-marital childbearing or family dissolution rather than migration, suggests that father absence is closely linked to socio-emotional development problems and particularly to greater externalizing problems (McLanahan, Tach, and Schneider 2013, 17). The implications of family disruption may be different for girls' and boys' socioemotional development (for a recent critical review, see Brenøe and Lundberg (2018)).

Finally, existing literature also evaluates the short-term effects of parental absence on left-behind children's academic performance, with inconsistent findings. For example, a study using data from the 2007 and 2009 Young Lives surveys shows that parental migration is linked to lower cognitive test scores in India and Vietnam (C. V. Nguyen 2016). But another study examines the impact of parental migration on children's academic performance in China using a pre- and postparental migration comparison design, and suggests a positive effect of parental migration on English test scores (Bai et al. 2018). These studies do not provide a consistent picture of shortterm educational outcomes linked to parental absence. Studies have yet to address longer-term implications of these short-term child developmental outcomes for children's educational attainment.

There are at least three major limitations in current literature. First, existing studies only focus on one or two mechanisms (implicitly using either a resource generation model or family disruption model) by which parental absence affects educational outcomes, such as the improvement of economic resources (Nguyen et al. 2006) or the lack of parental supervision (Lu 2012). This limitation not only hinders the understanding of how parental absence affects educational outcomes but may also lead to omitted variable bias - omitted mechanisms may be the true reasons for the detected effects. Second, each of the current studies only explores a small part of the diverse domains of home environment and child development, and thus different studies find different and sometimes opposing effects of parental absence. Without a simultaneous examination of diverse home-environment and child-development mechanisms of impact or effect pathways, we can neither calculate the overall effect of parental absence nor evaluate the relative importance of a specific impact. Finally, most studies stop at only revealing the shortterm consequences of parental absence but fail to link these short-term consequences to children's long-term developmental outcomes. Thus, whether the positive or negative impacts of parental absence are merely temporary or have longstanding implications is still unknown.

Given these limitations, we propose a framework to analyze the long-term implications of parental absence for children's educational attainment via distinct mechanisms. The framework synthesizes both the resource generation model and the family disruption model and incorporates diverse home-environment and child-development mechanisms. Home environment contains four domains: economic capital, human capital, social capital, and cultural capital. Child development comprises two short-term indicators: educational achievement and non-cognitive skills.

Our theoretical framework is depicted in Figure 1. In this framework, father absence may have a direct impact on children's educational attainment over time. More importantly, father absence affects home environment and child development, both of which further affect educational 
attainment. Moreover, home environment can also influence the short-term outcomes of child development. It should be noted that different home-environment and child-development mechanisms are not isolated but correlated, which for the simplicity of presentation is not shown in Figure 1 but is included in our analytic models.

(Figure 1)

To our knowledge, the current paper is the first to adopt a framework that links the resource generation and family disruption models in the migration literature to critical domains of child home environment drawn from the sociology of education literature. The paper incorporates short- and long-term influences of parental absence, allows for connections between different mechanisms, facilitates the identification of multiple pathways linking father absence to educational attainment, and enables calculation of the relative importance of each effect pathway. Guided by this framework and capitalizing on a 15-year longitudinal study of children in China, we pose three questions: First, is parental absence in childhood associated with children's long-term educational attainment? Second, what are the most significant pathways that link parental absence to children's educational attainment? Finally, given both the history of son preference in China and literature elsewhere (e.g., Brenøe and Lundberg 2018) suggesting that girls and boys may be differently vulnerable to family disruption, we pose a third question: are there gender differences in the overall association or in the particular pathways linking parental absence and children's long-term educational attainment?

\section{The China Context}

In 2010, 61 million children in China were left behind by one of their parents $-21.88 \%$ of China's children and nearly the total number of children in the United States in 2010 (All China Women's Federation and National Bureau of Statistics of China 2016; Zhou et al. 2014). The massive number of left-behind children in China is a product of two phenomena: first, the decision of increasing numbers of rural residents to move into cities for work and, second, the decision of migrants not to bring children with them. The first of these phenomena can be credited to a shift from a collective, planned economy to a private, market economy. This economic shift initiated in 1978, and over time reduced state control over labor mobility (Chang et al. 2011). The second of these phenomena can be traced to persisting policy barriers that ban or limit migrant workers' children's access to education in destination cities. These barriers have meant that with rising numbers of migrant workers has come a rising number of children left behind.

\section{Data and Methods}

\section{Data}

The study site for our study is rural Gansu, which was an impoverished province in northwest China. Gansu was a majority rural province with over $60 \%$ of the population residing in rural areas even in 2010 (Shen, Hu, and Hannum 2017). Economic hardship might push rural residents in Gansu to out-migrate to more developed cities for better jobs and higher income. Meanwhile, gender disparities in educational opportunities and gender differences in parental spending on children's education are more salient in resource-constrained regions and families (Hannum, 
Kong, and Zhang 2009; Connelly and Zheng 2003). Thus, Gansu provides an appropriate case for our study.

To answer the three questions listed in the preceding section, we analyze data from the 2000 and 2015 rounds of the Gansu Survey of Children and Families (GSCF, 2000, 2015), a longitudinal study of 2,000 children in 100 rural villages in China's Northwest. The sample drawn was a multi-stage cluster sample of rural households with children in the target age range. The children were first interviewed at ages 9 to 12 in the year 2000 and last interviewed in early adulthood in the year 2015. The initial questionnaires were administered at schools and in homes to children, teachers, school principals, mothers, and household heads. By the year 2015, all children should have finished formal schooling and thus finalized their educational attainment. In 2015, 1,613 now-adult children of the initial sample were successfully followed up. Although the GSCF is not nationally representative, the unique 15-year timespan makes it the sole dataset on child development in China that can link childhood experiences with adulthood outcomes. ${ }^{4}$

\section{Measurement}

\section{Educational Attainment and Father Absence}

The key dependent variable in this study is children's educational attainment. In the 2015 survey, respondents were asked about their highest degree of education attained. Based on their responses, we generate a continuous measure of total years of education attained, with an average of 11.387 years. ${ }^{5}$ Since the measure of educational attainment in 2015 had many missing

\footnotetext{
${ }^{4}$ We focus on data collected in 2000 and 2015 for this study. GSCF collected data also in 2004, 2007, and 2009. The 2007 wave focused on target children's siblings and the 2009 wave focused on target children's employment and educational outcomes, both of which did not include the measures of different home-environment and child-development mechanisms examined in this study. The 2004 wave was similar to the initial wave which contained the measures of most mechanisms examined in this study. However, in 2004, 16.1\% of children dropped out or had no enrollment status which made the measure of educational achievement unavailable. Those missing observations on educational achievement cannot be handled by missing data techniques and would greatly reduce the analytical sample. As the method employed in this study (structural equation modeling, as discussed in the following section) requires a large sample size for efficient and unbiased estimates (Kline 2015), the reduced sample would have greatly diminished the power of this study. For this reason, we did not include the 2004 data. In addition, parental migration status in 2004 did not differ significantly from that in 2000 . In 2004, $98.35 \%$ of mothers stayed at home and only $8.83 \%$ of resident fathers in 2000 became migrants in 2004, which provided too few cases to do within-family comparison to trace the changes in family context due to parental absence. Moreover, our research goal is not to trace temporal changes in parental absence, but to identify diverse possible mechanisms linking parental absence in childhood to long-term educational attainment. Thus, the use of the first and last rounds of data collection can fulfil our research goal. ${ }^{5}$ In Shen, Hu, and Hannum (2017) which used the same dataset, the average of educational attainment was 11.24 years. This slight difference in the average results from different coding strategies for the degree category "secondary trade school/technical school/vocational high school". The time required for a degree in secondary trade school/technical school/vocational high school ranges from 2 years to 3 years, and thus the total years of education for this category also varies from 11 to 12 years. Shen, $\mathrm{Hu}$, and Hannum (2017) adopted the minimum years which distinguished this category from "high school" (12 years), while in this paper we adopted the maximum years which is consistent with the coding strategy used in another dataset - the China Family Panel Studies (Xie et al. 2012).
} 
values, we use the years of education completed in 2009 as an auxiliary variable - a variable used for improving the procedure of handling missing data but not included in the analytical model. The auxiliary variable can be correlated with the educational attainment measurement that have missing values, regardless of its correlation with the mechanism of missingness (Collins, Schafer, and Kam 2001). In a longitudinal study, an ideal auxiliary variable is often the same variable measured at a different time point, given the strong dependence or correlation between these two measures (Collins, Schafer, and Kam 2001). The average years of educational attainment in 2009 was 9.527 years, and its correlation coefficient with educational attainment in 2015 was 0.727 , which suggests it is a good auxiliary variable.

All variables other than educational attainment were measured in the year 2000. In the 2000 baseline survey, parents were asked about the months of residence at home during the last year. When defining parental absence, the current literature usually adopts six months of absence as the criterion (De Brauw and Mu 2011; Graham and Jordan 2011; Nguyen 2016; Sun and Wang 2016). Following this rule, parents who lived at home for six months or fewer during the last year (i.e., absent for at least six months) were defined as being absent. According to this definition, $19.6 \%$ of children were father-absent while only $1.7 \%$ of children were mother-absent in the year 2000. Because of the extremely low proportion of mother absence in 2000, we focus exclusively on father absence. Father absence is a binary variable, with 1 denoting father absence (treatment) and 0 denoting no father absence (control).

\section{Home Environment}

We evaluate four domains of home environment in the year 2000: economic capital, human capital, social capital, and cultural capital. Economic capital as monetary resources is often measured by income (Anheier, Gerhards, and Romo 1995; Møllegaard and Jæger 2015). In our data, family economic capital was measured by the logged family income per capita. Family income per capita denoted the total of income during the last year from different sources (wages, farm and forest production, livestock farming, and self-employment), divided by family size. To adjust for the nonlinear effect of extreme values of income (Ermini and Hendry 2008), we converted family income per capita into the logarithm form.

Human capital is often operationalized as education (Coleman 1988; Teachman, Paasch, and Carver 1997). To capture the characteristic of the whole family environment in which children grow up, we did not limit the measure of human capital to parents but all adults living at home. Since the older generations' educational levels were low in impoverished rural areas and many did not receive formal education (Stites and Semali 1991), we chose literacy (i.e., reading ability) as an indicator of education. Thus, family human capital in our study was measured by the number of adults (parents, uncles, aunts, and grandparents) present in the home with reading ability. A father at home contributes a " 1 " to this measure if he is literate and a " 0 " if not. Representing a human capital loss associated with migration, a literate yet absent father contributes a " 0 ".

Social capital is embedded in the bonds and interactions between children and parents/adults (Parcel and Menaghan 1994). Thus, social capital consisted of two parts: the bonds between children and parents, measured by the widely used concept of "parental warmth" (Hartas 2015), and the interactions between children and parents/adults measured by "parents or other adults at 
home doing things together with children" (Clark and Lisowski 2018; Xinguang Chen et al. 2015). Parental warmth usually represents parental support and care, including encouragement, positive reinforcement, active involvement in children's lives, and appropriate monitoring (Pettit et al. 1997). Parental warmth is significantly associated with children's developmental outcomes. For example, a recent study in China finds that parental warmth as an indicator of parenting practice mediates parental migration and left-behind children's behavioral problems (Lu et al. 2019).

In this paper, parental warmth is a summative scale of 18 items such as "your parents encourage you to think independently" or "your parents are always gentle with you" (for development of parental warmth items, see J. J.-L. Chen and Liu 2012, 491; X. Liu 2003). These 18 items were answered by children on a 3-point Likert scale (1 to 3: never, sometimes, often) with a higher score indicating more parental support. The Cronbach's alpha for the parental warmth scale was 0.77. ${ }^{6}$ Parents or other adults at home doing things together with children was measured by the 5 following activities: reading story books, helping with assignments, playing games, going to bookstores, and discussing things that children were interested in. Children indicated the frequency ( 1 to 3 : never, sometimes, often) of each activity with a higher score meaning more frequent. These five items were combined into a single scale, for which the Cronbach's alpha was 0.70 .

The last aspect of home environment considered here is cultural capital. This paper adopts the "DiMaggio tradition" of conceptualizing cultural capital as resources that shape student outcomes (Davies and Rizk 2017). ${ }^{7}$ We operationalize cultural resources as the number of books that children possess, including schoolbooks, magazines, and other books. All of the home environment variables were measured in the year 2000, when father absence had occurred.

\section{Child Development}

We explore two categories of child development: educational achievement and non-cognitive skills. Children's educational achievement is denoted by the average of teacher-reported Chinese and math grades in the preceding semester, both measured with a scale from 0 to 100 . Noncognitive skills are measured by behavioral problems in a culturally adapted scale based on the Child Youth Self Report (Achenbach 1991) (for development and testing of these measures, see

\footnotetext{
${ }^{6}$ Prior research using the Gansu Survey of Children and Families has linked parenting style (warmth or communicative parenting) to fewer externalizing problems outcomes (J. J.-L. Chen and Liu 2012) and to persisting in school to the high school entrance examination (T. Sargent, Kong, and Zhang 2014).

${ }^{7}$ Work by other scholars in Gansu Province has addressed the alternative traditions of cultural capital research defined by Davies and Rizk (2017). Sargent's (2009) mixed-methods application of social interaction theory to curricular and pedagogical reform in rural Gansu schools is characterized by Davies and Rizk $(2017,15)$ as falling into the Collins tradition. Kong's (2016) ethnographic account of the challenges faced by socioeconomically disadvantaged rural parents in engaging with schools in expected ways, and the alternate, sometimes-invisible strategies these families do deploy, might be viewed as broadly akin to the Lareau tradition as defined in Davies and Rizk (2017). In a similar vein, Li's (2019) introduction to a special issue of Chinese Education and Society on rural student success suggests that the distance between nationally-defined, urban-oriented school standards and rural life creates shortfalls in "mainstream" cultural capital for rural students, but he points to non-dominant forms of cultural capital in rural society that can facilitate rural youth success.
} 
J. J.-L. Chen and Liu 2012, 490-92; X. Liu 2003). Two types of behavioral problems are included: internalizing problems and externalizing problems. Internalizing problems are innerdirected behavioral problems such as withdrawal and anxiety, while externalizing problems are outer-directed behavioral problems that reflect children's negative actions directed toward the external environment, such as delinquent and aggressive behaviors (Eisenberg et al. 2001). The Cronbach's alpha scores were 0.82 for internalizing problems and 0.88 for externalizing problems, respectively. Just as for the home environment variables described above, all of these child development variables were measured in the year 2000, when father absence had occurred. Thus, the possible influences of father absence on child development variables were also captured in these measures.

\section{Covariates in the Propensity Score Model}

Variables included in the propensity score model should be those theoretically correlated with either the outcome (educational attainment) or both the outcome and the treatment (father absence), no matter whether such correlations are statistically significant in the dataset (Wyss et al. 2013; Rubin and Thomas 1996; W. Leite 2016). Therefore, we include in the propensity score model the covariates of child demographics (age and gender), family structure (sibship size), children's education and health, and the household's economic, cultural, and social capital.

Children's education was a binary indicator of retention experience in the period from first grade to one year prior to father absence. Children's health was denoted by a binary variable of diagnosed chronic disease in the past. We measure family economic capital by the value of fixed assets and durable goods in each household, which included 38 items such as cars and sewing machines, among others. Compared with income, the value of fixed assets and durable goods was a more reliable economic indicator prior to father absence. Family cultural capital was composed of father's and mother's years of education. Family social capital was measured by mother's evaluation of neighbor relationship in the village (1-3: not good, normal, very good). All of these covariates were indicators prior to father absence and had no missing values. All the variables used in the propensity score model and the outcome model are summarized in Table 1.

(Table 1)

\section{Method and Analytical Strategy}

Structural equation modeling (SEM) with inverse probability of treatment weighting (IPTW) is utilized for analysis. Compared with conventional regression methods, SEM features the following advantages. First, its capability of simultaneously estimating different equations enables us to explore how father absence may affect educational attainment through different pathways - home-environment and child-development mechanisms. Second, it has a convenient and powerful technique of handling missing data, i.e., the full information maximum likelihood (FIML) method. ${ }^{8}$ Third, the multiple group analysis in SEM can estimate the same model for different subgroups simultaneously, which facilitates the comparison between girls and boys for

\footnotetext{
${ }^{8}$ Compared with conventional multiple imputation which uses two models (imputation model and analysis model) that may produce incompatibility, handing missing data in SEM with FIML method only uses one model - the real analysis model, which makes results unaffected by the imputation model, and the results are also asymptotically efficient (Allison 2015).
} 
all of the parameters of interest. Given these advantages, SEM is our preferred method for investigating the long-term impacts of father absence on children's educational attainment. ${ }^{9}$

In addition, inverse probability of treatment weighting is employed to reduce selection bias. Inverse probability of treatment weighting creates a pseudo-population in which the distributions of confounders are the same for the treated and untreated groups, and thus there is no longer an association between confounders and treatment, which makes the crude association between treatment and outcome unconfounded (Funk et al. 2011; Greenland, Robins, and Pearl 1999; L. Liu et al. 2019). Compared with matching, two advantages of inverse probability of treatment weighting make it a better bias-reduction method for this study. First, it has the flexibility of allowing for almost any analytical model in the outcome analysis, such as SEM. Second, it keeps the original sample size without dropping the unmatched cases, which is particularly attractive for this study since SEM requires a larger sample size than conventional regression methods (Kline 2015). We use STATA 15 to estimate the inverse probability weights and SEM models.

There are four steps in our analysis. First, we begin with a baseline unweighted SEM regressing educational attainment on father absence. With this approach, we do not seek to reveal a causal link between father absence and educational attainment, but instead to display an overall picture of whether father-absent children are disadvantaged in educational attainment. The baseline model includes child demographics (age and gender) as control variables. Also, since educational attainment in 2015 has a relatively high proportion of missing values, a strong auxiliary variable - educational attainment in 2009 (correlation coefficient is 0.727 ) - is used to improve model efficiency and reduce estimation bias (J. Graham 2003). Following the typical use of an auxiliary variable, this auxiliary variable is modeled to be correlated with all other variables but not used in the model predicting educational attainment in 2015.

Next, we estimate the propensity score of father absence. In a multilevel research design, the reduction of selection bias due to clustering can be achieved by accounting for clustering effect in the propensity score model (F. Li, Zaslavsky, and Landrum 2013; W. L. Leite et al. 2015). Therefore, we use a random intercept multilevel logistic regression to estimate the propensity score of father absence. The propensity score is the predicted probability of father absence estimated from the logistic model. After that, an inverse probability weight is calculated for each case. For cases in the treatment (i.e., father absence) group, the inverse probability weight is calculated as 1/predicted probability; for cases in the control group, the inverse probability weight is calculated as $1 /(1-$ predicted probability $)$. To further reduce bias due to large and influential weights, we use the stabilized weights proposed by Robins, Hernán, and Brumback (2000). The stabilized weight for each case is the product of the initial weight and the mean of these initial weights in that case's group (i.e., treatment or control group). After obtaining the stabilized weights, we use father absence as the sole independent variable to run weighted linear regression (continuous covariate as the dependent variable) or weighted logistic regression (binary covariate as the dependent variable) to check data balance to ensure that weighing has removed data imbalance and corrected for selection (Guo and Fraser 2015).

\footnotetext{
${ }^{9}$ SEM also has a goodness-of-fit test for the whole model. However, these goodness-of-fit test statistics are not available in STATA due to the use of robust standard errors in this study.
} 
Third, using the stabilized weights calculated in the second step, we conduct a weighted SEM analysis to identify distinct, significant pathways that link father absence to educational attainment. In this step, different aspects of home environment and child development, affected by father absence, serve as predictors of educational attainment. Therefore, except for child demographics, all covariates about family conditions utilized in the propensity score model are no longer included. This is consistent with the model specification suggestion that the outcome model and the propensity score model rarely have the same set of covariates (Freedman and Berk 2008; Guo and Fraser 2015). As in the baseline model, full information maximum likelihood and the auxiliary variable of educational attainment are also used to handle missing data for better model estimation (Allison 2015; J. Graham 2003).

In addition, home-environment and child-development mechanisms are not isolated but correlated. For instance, family economic capital as a critical component of family SES affects all other aspects of home environment and child development. In particular, economic capital may influence human capital for the reason that a family's economic capital determines the affordable number of cohabitants in the family, which overlaps with human capital measured by the number of adults at home with reading ability. Cultural capital, measured by the number of books, can be influenced by human capital - adults at home with reading ability (Jager and Breen 2016). Furthermore, one form of social capital - doing things together with parents or other adults at home - contains intellectual activities like reading story books and helping with assignments, which should also be affected by human capital at home. All aspects of home environment affect child development. Within the domain of child development, children's behavioral problems also have an impact on educational achievement. Figure 2 describes the detailed specification of the model.

(Figure 2)

Finally, based on the model in the third step, we conduct a multiple group analysis to examine whether there are gender differences in the overall association and the specific pathways linking father absence and educational attainment. We use full information maximum likelihood (FIML) to handle missing data. Due to the use of robust standard errors, the goodness-of-fit test statistics are no longer available in STATA and thus not reported in this paper.

\section{Results}

\section{Father Absence and Educational Attainment}

Table 2 shows the results from the baseline model, which estimates the long-term association of father absence with children's educational attainment. After controlling for child demographics (age and gender), father-absent children have 0.510 years fewer total years of education attained. This finding suggests father absence in childhood has a non-trivial long-term negative association with children's educational attainment. We turn next to investigating mechanisms.

(Table 2)

\section{Data Balance}

Before the investigation of mechanism, we address the selectivity of migration by estimating the propensity score model first and calculating the stabilized inversed probability weights. Table 3 
displays data imbalance before weighting and data balance after weighting. In this step, father absence as the sole independent variable predicts each covariate using bivariate linear regression or logistic regression. Before applying weights, all covariates are not significantly related to father absence, except for family economic capital - fixed assets and durable goods. This result suggests that father's labor migration is largely an economic decision based on prior family economic conditions: fathers from poorer families have a higher likelihood of absence or migration for work. After weighting, none of these covariates has a significant association with father absence and all their standard errors increase. This result indicates that weighting has successfully balanced our data.

(Table 3)

\section{Significant Pathways Linking Father Absence to Educational Attainment}

With data balance achieved, we apply the stabilized inverse probability weights to structural equation models depicted in Figure 2. The results are listed in Table A1 in appendix. To get a clear picture of the complex results shown in Table A1, we identify all the significant pathways linking father absence to children's educational attainment. We define a significant pathway as a pathway from father absence to children's educational attainment in which all coefficients are statistically significant at least at the $\mathrm{p}<0.05$ level. All of the identified significant pathways are described in Table 4 and illustrated in Figure 3. Our model suggests that the measured effects of father absence are largely flowing through the significant indirect mechanisms - the effect pathways - specified in Table 4, which sum to an effect of just about over a third of a year (0.342 years). With these pathways included in the model, father absence has no remaining significant direct impact on educational attainment.

Specifically, father absence is associated with more economic capital (family income per capita), which promotes educational attainment not only by itself but also through its direct impacts on human capital (adults at home with reading ability) and cultural capital (number of books) - the latter two's effects on educational attainment mainly operate through educational achievement. In total, the advantage in economic capital brought by father absence corresponds to a 0.175 -year increase in educational attainment.

Father absence also corresponds to a reduction of human capital at home. The loss in human capital due to father absence, in addition to directly reducing educational attainment, also reduces cultural capital (number of books) and educational achievement, both of which further lower educational attainment. In total, the loss in human capital due to father absence leads to a decrease of 0.517 years in educational attainment.

Putting these significant pathways together, we find that father absence in childhood is associated with 0.342 fewer years of educational attainment. Among all of the homeenvironment and child-development mechanisms, the loss in human capital has the largest detrimental effect ( -0.517 years) on children's educational attainment - even the positive effect ( 0.175 years) of economic capital can only offset about one third of such a large negative effect. One reason could be that in rural children's homes in China, fathers are usually the adult household members with the highest level of education. In our Gansu case, only $8.7 \%$ of 
households had more-educated mothers than fathers. ${ }^{10}$ Therefore, father absence often means the loss of the most educated adult in the household, which can bring substantial detrimental implications for children's educational attainment.

It is worth noting that in Table 4, a longer pathway (i.e., the one with more mediators) usually has a smaller effect size, which is to be expected since most mediators have smaller-than-1 coefficients. The effect size of a long pathway may also be statistical insignificant. But a small effect size or statistical insignificance in Table 4 does not necessarily negate the possibility of a long pathway. As clarified in the preceding section, the identification of each pathway shown in Table 4 has already passed a series of significance tests (i.e., each coefficient on a pathway should be significant at least at $\mathrm{p}<0.05)$. The additional significance test in Table 4 provides supplemental information to evaluate the effect size of each pathway, not to invalidate them. Moreover, these pathways provide needed insights about possible mechanisms linking parental absence to educational attainment, which may become more significant both practically and statistically in other studies using different datasets.

(Table 4)

(Figure 3)

\section{Gender Differences}

To examine whether there are gender differences in the overall association and particular pathways linking father absence and children's educational attainment, we conduct a multiple group analysis, which estimates results for males and females simultaneously. In this case, gender is no longer a control variable in the model.

Each gender model has about half of the original sample size (928 females and 1,072 males), which is too small to accurately estimate all the parameters in the full model. Thus, we keep only those significant effect pathways identified in the full model and then estimate them again for both males and females. In this way, we could detect potential gender differences in the significant effect pathways.

The specific effect pathways for males and females are summarized in Table 5 and Figure 4, and the detailed results from the gender-difference model are appended in Table A2. Two main findings emerge. First, overall, father absence corresponds to a reduction in educational attainment of 0.496 years for boys and 0.244 years for girls, but only the reduction for boys is statistically significant. Second, the economic capital brought by father absence benefits girls to a large extent but has little benefit for boys. On average, father absence leads to an increase of 0.413 years in girls' educational attainment but only 0.018 years in boys' educational attainment through the gain in economic capital. In short, these results suggest that father absence hurts boys more than girls in terms of educational attainment.

These results are consistent with a prior literature on poverty and gender disparities in education. While China has experienced a long-term decline in girls' disadvantage in educational

${ }^{10}$ For $52.25 \%$ families, fathers had higher levels of education than mothers did. For $39.05 \%$ families, fathers and mothers had the same level of education. 
attainment $^{11}$, prior literature has suggested that when economic resources are limited, families have tended to invest in boys' education but sacrifice girls' education (Hannum and Xie 1994; Hannum 2005; Wu and Zhang 2010). Rural women's poorer access to cash income combined with a culture of patrilocal marriage and intergenerational co-residence as a means of old age support to incentivize families facing economic pressure to prioritize education of boys (Lin 1993; Brown and Park 2002; Michelson and Parish 2000; Hannum, Kong, and Zhang 2009). For these reasons, girls' educational opportunities have been more responsive than boys' to better family economic resources (Hannum 2005). In this context, it is not surprising to see that the increased family income brought by father absence benefits girls' education more than boys' education.

Although the concrete mechanisms are unclear, research elsewhere has suggested that boys are more likely than girls to be affected by a disadvantaged family background or environment (McDaniel 2012). For example, in the United States, Buchmann and DiPrete (2006) find that boys whose fathers are less educated or absent from home are particularly vulnerable in educational attainment, which contributes to the male disadvantage in college completion. Consistent with this finding, another study of left-behind children in China finds that the negative effect of parental absence on left-behind children's education is only significant for boys and not for girls (Zhou, Murphy, and Tao 2014). Our finding that father absence hurts boys more than girls in terms of educational attainment is consistent with these studies.

(Table 5)

(Figure 4)

\section{Discussion and Conclusion}

In this paper, we propose a framework that allows for differential effects of migration on children's long-term outcomes via effects on the home environment and their immediate implications for child development. We apply structural equation models with inverse probability of treatment weighting to analyze data from the 2000 and 2015 rounds of the Gansu Survey of Children and Families (GSCF). Results show that father absence is negatively associated with children's long-term educational attainment. Most significantly, father absence is linked to reduced human capital at home, which has detrimental effects on children's educational attainment. At the same time, father absence is linked to better family economic resources, which is positively associated with children's educational attainment. When the father is absent, the mother may pay more attention to and show more love to children, which partially buffers the negative influence of father absence. Overall, results suggest that the loss of human capital at home resulting from father absence is the most important effect pathway linking father absence to educational attainment. Other positive influences of father absence, collectively, can only offset a small fraction--about a third--of this negative effect.

Finally, there are gender differences in effects and effect pathways. Greater family income in father-absent households benefits girls' educational attainment more than boys'. The underlying reason could be that impoverished families tend to guarantee boys' education with their limited economic resources and then invest more in girls' education when economic situation improves.

\footnotetext{
${ }^{11} \mathrm{Wu}$ and Zhang (2010) report that the gender gap in college enrollment was even reversed to favor women by 2005 .
} 
Such a finding is consistent with previous literature that resource-constrained families tend to prioritize boys' education over girls' education (Michelson and Parish 2000) and girls' education is more responsive to improvement in family economic resources (Hannum 2005). It should also be noted that such a difference in response to changed family economic resources found in rural Gansu might apply to similarly impoverished regions but not be generalized to more wealthier regions, since gender gaps in educational opportunities and gender differences in parental educational investment are larger in poor households (Filmer 1999; Connelly and Zheng 2003) but disappear in urban areas where the households are more wealthy than rural households (Tsui and Rich 2002). Finally, boys are more vulnerable than girls to father absence - father absence results in a larger reduction of total years of education for boys than for girls $(0.496$ years versus 0.244 years).

Due to data constraints, our research has some limitations. First, we have had to focus on father absence since only a small proportion of families in our sample had absent mothers. But our theoretical framework can be easily adapted to include mother absence or dual parent absence. Second, although in our analyses we mention the changes in family context associated with migrant fathers, what are measured in our dataset are essentially the differences between migrant and other families. Though the GSCF is a longitudinal dataset, there is little change in families' migration status - in the second wave (2004) $98.35 \%$ of mothers stayed at home and only $8.83 \%$ of resident fathers in 2000 became migrants in 2004, which provides too few cases to do withinfamily comparisons to trace the changes in family context due to parental absence. Thus, in this paper we have to employ a conventional technique like the one used in counterfactual analysis taking non-migrant families as the control group to approximate the unmeasured pre-migration family context. Finally, despite the application of inverse probability weighting and the occasional use of words like "effect", we are not making causal arguments. Causation requires a more rigorous research design, which we will leave for future work. Rather, we are proposing a new framework which can provide a holistic review of how parental migration may associate with children's long-term educational outcomes.

From a theoretical perspective, our analytical framework is useful in incorporating short-term and long-term perspectives and allowing for distinct effect pathways of parental absence via home-environment and child-development mechanisms. Furthermore, it allows for the connection and competition between different mechanisms underlying the association between parental absence and educational attainment, with each mechanism playing a controlling or mediating role for others, which helps to yield a more accurate estimate of each mechanism's effect. In addition, our framework enables the calculation and comparison of the relative importance of different effects and consequences, which facilitates a more comprehensive evaluation of the overall impact of parental absence and allows for assessment of group-specific heterogeneity of effects. Although our paper focuses on the case of China, this framework could be adapted to study the long-term impacts of parental migration on a series of outcomes in different countries or regions.

Findings from this study are also relevant for informing policy and practice in China, to address the needs of left-behind children. While previous research shows both positive and negative effects of parental absence on children's educational and developmental outcomes, this paper finds that the loss in human capital due to father absence has the largest negative effect on 
children's educational attainment. This effect cannot be offset by other positive factors associated with father absence. Given the great importance of parental human capital for children's long-term educational outcomes, reducing policy barriers to schooling at destination cities so that children can remain together with parents is one obvious way to promote children's education and human capital accumulation. In the absence of such a policy, initiatives to provide more institutionalized academic support and advising to left-behind children are important, whether through the current policy response of boarding schools, if well managed (Xiao et al. 2010), or other full-service schools tailored to address the needs of children whose caregivers have limited experience with the educational system. 


\section{References}

Achenbach, Thomas M. 1991. Manual for the Youth Self-Report and 1991 Profile. Department of Psychiatry, University of Vermont Burlington, VT.

Adams, Richard H. Jr, Alfredo Cuecuecha, and John Page. 2008. The Impact of Remittances on Poverty and Inequality in Ghana. The World Bank.

Adhikari, Ramesh, Aree Jampaklay, Aphichat Chamratrithirong, Kerry Richter, Umaporn Pattaravanich, and Patama Vapattanawong. 2014. "The Impact of Parental Migration on the Mental Health of Children Left Behind." Journal of Immigrant and Minority Health 16 (5): 781-89.

All China Women's Federation, and National Bureau of Statistics of China. 2016. "Number of Migrant Worker Children Growing up Away from Their Parents in China in 2005 and 2010." Statista. 2016. https://proxy.library.upenn.edu:3875/statistics/258437/number-ofleft-behind-children-in-china-by-age-group/.

Allison, Paul. 2015. "Maximum Likelihood Is Better than Multiple Imputation: Part II." Statistical Horizons. May 5, 2015. https://statisticalhorizons.com/ml-is-better-than-mi.

Anheier, Helmut K., Jurgen Gerhards, and Frank P. Romo. 1995. "Forms of Capital and Social Structure in Cultural Fields: Examining Bourdieu's Social Topography.” American Journal of Sociology 100 (4): 859-903.

Antman, Francisca M. 2012. "Gender, Educational Attainment, and the Impact of Parental Migration on Children Left Behind.” Journal of Population Economics 25 (4): 11871214.

Arguillas, Marie Joy B., and Lindy Williams. 2010. “The Impact of Parents' Overseas Employment on Educational Outcomes of Filipino Children.” International Migration Review 44 (2): 300-319.

Bai, Yu, Linxiu Zhang, Chengfang Liu, Yaojiang Shi, Di Mo, and Scott Rozelle. 2018. "Effect of Parental Migration on the Academic Performance of Left behind Children in North Western China." The Journal of Development Studies 54 (7): 1154-70.

Bourdieu, Pierre. 1986. "The Forms of Capital." In Handbook of Theory and Research for the Sociology of Education, edited by John G. Richardson, 241-58. New York: Greenwood Publising Group.

Brenøe, Anne Ardila, and Shelly Lundberg. 2018. "Gender Gaps in the Effects of Childhood Family Environment: Do They Persist into Adulthood?" European Economic Review 109 (October): 42-62.

Brown, Philip H. 2006. "Parental Education and Investment in Children's Human Capital in Rural China." Economic Development and Cultural Change 54 (4): 759-89.

Brown, Philip H., and Albert Park. 2002. "Education and Poverty in Rural China." Economics of Education Review 21 (6): 523-41.

Buchmann, Claudia, and Thomas A. DiPrete. 2006. "The Growing Female Advantage in College Completion: The Role of Family Background and Academic Achievement." American Sociological Review 71 (4): 515-41.

Carling, Jørgen, Cecilia Menjívar, and Leah Schmalzbauer. 2012. "Central Themes in the Study of Transnational Parenthood." Journal of Ethnic and Migration Studies 38 (2): 191-217.

Chang, Hongqin, Xiao-yuan Dong, and Fiona MacPhail. 2011. "Labor Migration and Time Use Patterns of the Left-behind Children and Elderly in Rural China." World Development 39 (12): 2199-2210. 
Chen, Jennifer Jun-Li, and Xiaodong Liu. 2012. "The Mediating Role of Perceived Parental Warmth and Parental Punishment in the Psychological Well-Being of Children in Rural China." Social Indicators Research 107 (3): 483-508.

Chen, Xinguang, Peigang Wang, Rhiana Wegner, Jie Gong, Xiaoyi Fang, and Linda Kaljee. 2015. "Measuring Social Capital Investment: Scale Development and Examination of Links to Social Capital and Perceived Stress.” Social Indicators Research 120 (3): 66987.

Chen, Xinyin, Dan Li, Junsheng Liu, Rui Fu, and Shihong Liu. 2019. "Father Migration and Mother Migration: Different Implications for Social, School, and Psychological Adjustment of Left-behind Children in Rural China." Journal of Contemporary China.

Clark, William AV, and William Lisowski. 2018. "Wellbeing across Individuals and Places: How Much Does Social Capital Matter?” Journal of Population Research 35 (3): 217 36.

Coleman, James S. 1988. "Social Capital in the Creation of Human Capital." American Journal of Sociology 94: S95-120.

Collins, Linda M., Joseph L. Schafer, and Chi-Ming Kam. 2001. "A Comparison of Inclusive and Restrictive Strategies in Modern Missing Data Procedures." Psychological Methods 6 (4): 330.

Connelly, Rachel, and Zhenzhen Zheng. 2003. "Determinants of School Enrollment and Completion of 10 to 18 Year Olds in China." Economics of Education Review 22 (4): 379-88.

Davies, Scott, and Jessica Rizk. 2017. "The Three Generations of Cultural Capital Research: A Narrative Review." Review of Educational Research, December, 88(3): 331-65.

De Brauw, Alan, and Ren Mu. 2011. "Migration and the Overweight and Underweight Status of Children in Rural China." Food Policy 36 (1): 88-100.

De Graaf, Nan Dirk, Paul M. De Graaf, and Gerbert Kraaykamp. 2000. "Parental Cultural Capital and Educational Attainment in the Netherlands: A Refinement of the Cultural Capital Perspective." Sociology of Education, 92-111.

DiMaggio, Paul. 1982. "Cultural Capital and School Success: The Impact of Status Culture Participation on the Grades of US High School Students." American Sociological Review, 189-201.

DiMaggio, Paul, and Toqir Mukhtar. 2004. "Arts Participation as Cultural Capital in the United States, 1982-2002: Signs of Decline?" Poetics 32 (2): 169-94.

Dreby, Joanna. 2010. Divided by Borders: Mexican Migrants and Their Children. Univ of California Press.

Eisenberg, Nancy, Amanda Cumberland, Tracy L. Spinrad, Richard A. Fabes, Stephanie A. Shepard, Mark Reiser, Bridget C. Murphy, Sandra H. Losoya, and Ivanna K. Guthrie. 2001. "The Relations of Regulation and Emotionality to Children's Externalizing and Internalizing Problem Behavior." Child Development 72 (4): 1112-34.

Ermini, Luigi, and David F. Hendry. 2008. "Log Income vs. Linear Income: An Application of the Encompassing Principle." Oxford Bulletin of Economics and Statistics 70: 807-27.

Fan, Cindy. 2008. "Migration, Hukou, and the City." In China Urbanizes: Consequences, Strategies, and Policies, edited by Shahid Yusuf and Anthony Saich, 65-89. Directions in Development. Countries and Regions. Washington, D.C: World Bank. 
Fan, Fang, Linyan Su, Mary Kay Gill, and Boris Birmaher. 2010. "Emotional and Behavioral Problems of Chinese Left-behind Children: A Preliminary Study.” Social Psychiatry and Psychiatric Epidemiology 45 (6): 655-64.

Fellmeth, Gracia, Kelly Rose-Clarke, Chenyue Zhao, Laura K. Busert, Yunting Zheng, Alessandro Massazza, Hacer Sonmez, et al. 2018. "Health Impacts of Parental Migration on Left-behind Children and Adolescents: A Systematic Review and Meta-Analysis." The Lancet 392 (10164): 2567-82.

Filmer, Deon. 1999. "The Structure of Social Disparities in Education: Gender and Wealth." No. 5. Gender and Development Working Paper Series. Washington, DC: World Bank.

Freedman, David A., and Richard A. Berk. 2008. "Weighting Regressions by Propensity Scores." Evaluation Review 32 (4): 392-409.

Funk, Michele Jonsson, Daniel Westreich, Chris Wiesen, Til Stürmer, M. Alan Brookhart, and Marie Davidian. 2011. "Doubly Robust Estimation of Causal Effects." American Journal of Epidemiology 173 (7): 761-67.

Graham, Elspeth, and Lucy P. Jordan. 2011. "Migrant Parents and the Psychological Well-Being of Left-behind Children in Southeast Asia." Journal of Marriage and Family 73 (4): $763-$ 87.

Graham, John. 2003. “Adding Missing-Data-Relevant Variables to FIML-Based Structural Equation Models." Structural Equation Modeling: A Multidisciplinary Journal 10 (1): 80-100.

Greenland, Sander, James M. Robins, and Judea Pearl. 1999. "Confounding and Collapsibility in Causal Inference." Statistical Science 14 (1): 29-46.

Guo, Shenyang, and Mark W. Fraser. 2015. Propensity Score Analysis. Sage.

Hadi, A. 1999. "Overseas Migration and the Well-Being of Those Left-behind in Rural Communities of Bangladesh." Asia-Pacific Population Journal 14 (1): 43-58.

Hannum, Emily. 2005. "Market Transition, Educational Disparities, and Family Strategies in Rural China: New Evidence on Gender Stratification and Development." Demography 42 (2): 275-99.

Hannum, Emily, Li-Chung Hu, and Wensong Shen. 2018. "Short- and Long-Term Outcomes of the Left behind in China: Education, Well-Being and Life Opportunities." Background Paper for Global Education Monitoring Report 2019. Paris: The United Nations Educational, Scientific and Cultural Organization.

Hannum, Emily, Peggy Kong, and Yuping Zhang. 2009. "Family Sources of Educational Gender Inequality in Rural China: A Critical Assessment." International Journal of Educational Development, Education and Development in Contemporary China, 29 (5): 474-86.

Hannum, Emily, and Yu Xie. 1994. "Trends in Educational Gender Inequality in China: 19491985." Research in Social Stratification and Mobility 13: 73-98.

Hartas, Dimitra. 2015. "Parenting for Social Mobility? Home Learning, Parental Warmth, Class and Educational Outcomes." Journal of Education Policy 30 (1): 21-38.

Jager, Mads Meier, and Richard Breen. 2016. "A Dynamic Model of Cultural Reproduction." American Journal of Sociology 121 (4): 1079-1115.

Jampaklay, Aree. 2006. "Parental Absence and Children's School Enrolment." Asian Population Studies 2 (1): 93-110.

Jones, Huw, and Sirinan Kittisuksathit. 2003. "International Labour Migration and Quality of Life: Findings from Rural Thailand." Population, Space and Place 9 (6): 517-30. 
Kline, Rex B. 2015. Principles and Practice of Structural Equation Modeling. 4th ed. New York: The Guilford Press.

Kong, Peggy A. 2016. Parenting, Education and Social Mobility in Rural China: Cultivating Dragons and Phoenixes. Routledge Contemporary China Series 134. London; New York: Routledge.

Lareau, Annette, and Erin McNamara Horvat. 1999. "Moments of Social Inclusion and Exclusion Race, Class, and Cultural Capital in Family-School Relationships." Sociology of Education, 37-53.

Lareau, Annette, and Elliot B. Weininger. 2003. "Cultural Capital in Educational Research: A Critical Assessment." Theory and Society 32 (5-6): 567-606.

Leite, Walter. 2016. Practical Propensity Score Methods Using R. Sage Publications.

Leite, Walter L., Francisco Jimenez, Yasemin Kaya, Laura M. Stapleton, Jann W. MacInnes, and Robert Sandbach. 2015. "An Evaluation of Weighting Methods Based on Propensity Scores to Reduce Selection Bias in Multilevel Observational Studies." Multivariate Behavioral Research 50 (3): 265-84.

Li, Fan, Alan M. Zaslavsky, and Mary Beth Landrum. 2013. "Propensity Score Weighting with Multilevel Data." Statistics in Medicine 32 (19): 3373-87.

Li, Xiaoliang. 2019. "Unpacking the Extraordinary Academic Success of Rural Students." Chinese Education and Society 52 (5-6): 297-300.

Liang, Zai. 2016. "China's Great Migration and the Prospects of a More Integrated Society." Annual Review of Sociology 42 (1): 451-71.

Lin, Jing. 1993. Education in Post-Mao China. Westport, Conn: Praeger.

Liu, Lan, Michael G. Hudgens, Bradley Saul, John D. Clemens, Mohammad Ali, and Michael E. Emch. 2019. "Doubly Robust Estimation in Observational Studies with Partial Interference." Stat 8 (1): e214.

Liu, Xiaodong. 2003. "Parenting Practices and the Psychological Adjustment of Children in Rural China." ProQuest Dissertations and Theses. Ed.D., Cambridge, MA: Harvard University. 305337977. ProQuest Dissertations \& Theses Global. https://repository.upenn.edu/gansu_dissertations/2/.

Lu, Yao. 2012. "Education of Children Left behind in Rural China." Journal of Marriage and Family 74 (2): 328-41. . 2014. "Parental Migration and Education of Left-Behind Children: A Comparison of Two Settings." Journal of Marriage and Family 76 (5): 1082-98.

Lu, Yao, and Donald J. Treiman. 2011. "Migration, Remittances and Educational Stratification among Blacks in Apartheid and Post-Apartheid South Africa." Social Forces 89 (4): 1119-43.

Lu, Yao, Jean Wei-Jun Yeung, Jingming Liu, and Donald J. Treiman. 2019. "Migration and Children's Psychosocial Development in China: When and Why Migration Matters." Social Science Research 77: 130-47.

Lu, Yao, Wei-Jun Jean Yeung, and Donald J. Treiman. 2020. "Parental Migration and Children's Psychological and Cognitive Development in China: Differences and Mediating Mechanisms." Chinese Sociological Review, 1-27.

Mazzucato, Valentina, Victor Cebotari, Angela Veale, Allen White, Marzia Grassi, and Jeanne Vivet. 2015. "International Parental Migration and the Psychological Well-Being of Children in Ghana, Nigeria, and Angola.” Social Science \& Medicine 132 (May): 21524. 
McDaniel, Anne. 2012. "Women's Advantage in Higher Education: Towards Understanding a Global Phenomenon.” Sociology Compass 6 (7): 581-95.

McLanahan, Sara, Laura Tach, and Daniel Schneider. 2013. "The Causal Effects of Father Absence." Annual Review of Sociology 39 (1): 399-427.

Meng, Xin, and Chikako Yamauchi. 2017. "Children of Migrants: The Cumulative Impact of Parental Migration on Children's Education and Health Outcomes in China." Demography 54 (5): 1677-1714.

Michelson, Ethan, and William Parish. 2000. "Gender Differentials in Economic Success: Rural China in 1991." In Re-Drawing Boundaries: Work, Households, and Gender in China, edited by Barbara Entwisle and Gail E. Henderson, 134-56. Berkely, California: University of California Press.

Møllegaard, Stine, and Mads Meier Jæger. 2015. "The Effect of Grandparents' Economic, Cultural, and Social Capital on Grandchildren's Educational Success." Research in Social Stratification and Mobility 42: 11-19.

Nguyen, Cuong Viet. 2016. "Does Parental Migration Really Benefit Left-behind Children? Comparative Evidence from Ethiopia, India, Peru and Vietnam.” Social Science \& Medicine 153 (March): 230-39.

Nguyen, Liem, Brenda SA Yeoh, and Mika Toyota. 2006. "Migration and the Well-Being of the 'Left behind'in Asia: Key Themes and Trends." Asian Population Studies 2 (1): 37-44.

Parcel, Toby L., and Elizabeth G. Menaghan. 1994. "Early Parental Work, Family Social Capital, and Early Childhood Outcomes." American Journal of Sociology 99 (4): 9721009.

Parreñas, Rhacel Salazar. 2005. Children of Global Migration: Transnational Families and Gendered Woes. Stanford University Press.

Pettit, Gregory S., John E. Bates, and Kenneth A. Dodge. 1997. "Supportive Parenting, Ecological Context, and Children's Adjustment: A Seven-Year Longitudinal Study." Child Development 68 (5): 908-23.

Qin, Jiang, and Björn Albin. 2010. "The Mental Health of Children Left behind in Rural China by Migrating Parents: A Literature Review." Journal of Public Mental Health 9 (3): 416.

Ren, Qiang, and Donald J. Treiman. 2016. "The Consequences of Parental Labor Migration in China for Children's Emotional Wellbeing." Social Science Research 58 (July): 46-67.

Robins, James M., Miguel Ángel Hernán, and Babette Brumback. 2000. "Marginal Structural Models and Causal Inference in Epidemiology." Epidemiology 11 (5): 550.

Rubin, Donald B., and Neal Thomas. 1996. "Matching Using Estimated Propensity Scores: Relating Theory to Practice." Biometrics, 249-64.

Sargent, Tanja Carmel. 2009. "Revolutionizing Ritual Interaction in the Classroom: Constructing the Chinese Renaissance of the Twenty-First Century." Modern China 35 (6): 632-61.

Sargent, Tanja, Peggy Kong, and Yuping Zhang. 2014. "Home Environment and Educational Transitions on the Path to College in Rural Northwest China." International Journal of Educational Development 34 (January): 98-109.

Shen, Wensong, Li-Chung Hu, and Emily Hannum. 2017. "Cumulative Adversity, Childhood Behavioral Problems, and Educational Mobility in China's Poorest Rural Communities." Chinese Journal of Sociology 3 (4): 491-517. 
Stites, Regie, and Ladislaus Semali. 1991. "Adult Literacy for Social Equality or Economic Growth? Changing Agendas for Mass Literacy in China and Tanzania." Comparative Education Review 35 (1): 44-75.

Sun, Wenkai, and Yijie Wang. 2016. "The Effect of Parental Absence for Work on Children's Health: A Micro Panel Data Analysis." China Economic Quarterly 15 (3): 963-88.

Teachman, Jay D., Kathleen Paasch, and Karen Carver. 1997. "Social Capital and the Generation of Human Capital." Social Forces 75 (4): 1343-59.

Tsui, Ming, and Lynne Rich. 2002. "The Only Child and Educational Opportunity for Girls in Urban China." Gender \& Society 16 (1): 74-92.

Wang, Shaoguang, Deborah Davis, and Yanjie Bian. 2006. "The Uneven Distribution of Cultural Capital: Book Reading in Urban China." Modern China 32 (3): 315-48.

Wen, Ming, Shaobing Su, Xiaoming Li, and Danhua Lin. 2015. "Positive Youth Development in Rural China: The Role of Parental Migration." Social Science \& Medicine 132 (May): 261-69.

Wu, Xiaogang, and Zhuoni Zhang. 2010. "Changes in Educational Inequality in China, 19902005: Evidence from the Population Census Data.” In , edited by Emily Hannum, Hyunjoon Park, and Yuko G. Butler, 17:123-52. Globalization, Changing Demographics, and Educational Challenges in East Asia. Emerald Group Publishing Limited.

Wyss, Richard, Cynthia J. Girman, Robert J. LoCasale, M. Alan Brookhart, and Til Stürmer. 2013. "Variable Selection for Propensity Score Models When Estimating Treatment Effects on Multiple Outcomes: A Simulation Study." Pharmacoepidemiology and Drug Safety 22 (1): 77-85.

Xiao, Min, Ying Ge, and Chenggang Cao. 2010. "Rural Boarding Schools and Their Relationship with Left-behind Children's Emotion Management and Mental Health." Chinese Journal of School Health, no. 11: 1294-96.

Xie, Yu, Qi Xu, Chunni Zhang, and Hongwei Xu. 2012. "China Family Panel Studies 2010 General Variables: Educational Attainment and Depression Scale.” China Family Panel Studies Technical Reports. http://www.isss.pku.edu.cn/cfps/docs/20180927133206956307.pdf.

$\mathrm{Xu}$, Hongwei, and Yu Xie. 2015. "The Causal Effects of Rural-to-Urban Migration on Children's Well-Being in China." European Sociological Review 31 (4): 502-19.

Yeung, Wei-Jun Jean, and Xiaorong Gu. 2016. "Left behind by Parents in China: Internal Migration and Adolescents' Well-Being." Marriage \& Family Review 52 (1-2): 127-61.

Young, Natalie A.E., and Emily C. Hannum. 2018. "Childhood Inequality in China: Evidence from Recent Survey Data (2012-2014).” The China Quarterly 236 (December): 1063-87.

Zhao, Meng, and Paul Glewwe. 2010. "What Determines Basic School Attainment in Developing Countries? Evidence from Rural China." Economics of Education Review 29 (3): 451-60.

Zhou, Minhui, Rachel Murphy, and Ran Tao. 2014. "Effects of Parents' Migration on the Education of Children Left behind in Rural China." Population and Development Review 40 (2): 273-92. 


\section{Tables and Figures}

Table 1 Descriptive Statistics

\begin{tabular}{|c|c|c|c|c|c|}
\hline & $\begin{array}{c}\text { Mean / } \\
\text { Proportion }\end{array}$ & SD & Min & $\operatorname{Max}$ & $\mathrm{N}$ \\
\hline \multicolumn{6}{|l|}{ Covariates in Propensity Score Model } \\
\hline \multicolumn{6}{|l|}{ Child Demographics } \\
\hline Age & 11.093 & 1.159 & 8 & 16 & 2000 \\
\hline Gender $($ male $=1$, female $=0)$ & 0.536 & & 0 & 1 & 2000 \\
\hline \multicolumn{6}{|l|}{ Family Structure } \\
\hline Sibship size & 2.247 & 0.749 & 0 & 5 & 2000 \\
\hline \multicolumn{6}{|l|}{ Child Health } \\
\hline Chronic disease & 0.023 & & 0 & 1 & 2000 \\
\hline \multicolumn{6}{|l|}{ Child Education } \\
\hline Retention & 0.151 & & 0 & 1 & 2000 \\
\hline \multicolumn{6}{|l|}{ Family Economic Capital } \\
\hline Fixed assets and durable goods & 6.686 & 11.144 & 0.057 & 153.760 & 2000 \\
\hline \multicolumn{6}{|l|}{ Family Cultural Capital } \\
\hline Father's years of education & 6.630 & 4.218 & 0 & 15 & 2000 \\
\hline Mother's years of education & 3.701 & 4.033 & 0 & 14 & 2000 \\
\hline \multicolumn{6}{|l|}{ Family Social Capital } \\
\hline Neighbor relationship in village & 2.536 & 0.517 & 1 & 3 & 2000 \\
\hline \multicolumn{6}{|l|}{ Key Variables in Outcome Model } \\
\hline Father Absence & 0.196 & & 0 & 1 & 2000 \\
\hline \multicolumn{6}{|l|}{ Economic Capital } \\
\hline Family income per capita (Log) & 0.058 & 0.898 & -4.605 & 4.398 & 2000 \\
\hline \multicolumn{6}{|l|}{ Human Capital } \\
\hline Adults at home with reading ability & 1.504 & 0.899 & 0 & 6 & 2000 \\
\hline \multicolumn{6}{|l|}{ Social Capital } \\
\hline Parental warmth & 38.748 & 5.364 & 18 & 54 & 1949 \\
\hline Doing things together & 9.277 & 2.038 & 5 & 15 & 1981 \\
\hline \multicolumn{6}{|l|}{ Cultural Capital } \\
\hline Number of books & 27.991 & 21.099 & 0 & 160 & 1803 \\
\hline \multicolumn{6}{|l|}{ Non-Cognitive Skills } \\
\hline Internalizing problems & 39.975 & 8.140 & 18 & 72 & 1970 \\
\hline Externalizing problems & 35.295 & 8.877 & 18 & 72 & 1976 \\
\hline \multicolumn{6}{|l|}{ Educational Achievement } \\
\hline Educational achievement & 73.247 & 13.223 & 0 & 100 & 1951 \\
\hline \multicolumn{6}{|l|}{ Educational Attainment } \\
\hline Years of education in 2015 & 11.387 & 3.537 & 0 & 19 & 1613 \\
\hline \multicolumn{6}{|l|}{ Auxiliary Variable } \\
\hline Years of education in 2009 & 9.527 & 2.339 & 0 & 12 & 1833 \\
\hline
\end{tabular}


Table 2 Maximum Likelihood Parameter Estimates in the Baseline Model of Predicting Educational Attainment by Father Absence

\begin{tabular}{|c|c|c|c|}
\hline Parameter & & & $\begin{array}{c}\text { Unstandardized } \\
\text { Coefficient }\end{array}$ \\
\hline Father Absence & & Educational Attainment & $\begin{array}{l}-0.510 * \\
(0.213)\end{array}$ \\
\hline Age & $\rightarrow$ & Educational Attainment & $\begin{array}{l}-0.056 \\
(0.074)\end{array}$ \\
\hline Male & $\rightarrow$ & Educational Attainment & $\begin{array}{l}0.501 * * \\
(0.169)\end{array}$ \\
\hline Observations & & & 2000 \\
\hline
\end{tabular}

Note: Robust standard errors in parentheses.

$*<.05, * *<.01, * * *<.001$ 
Table 3 Data Balance Check

\begin{tabular}{|c|c|c|}
\hline \multirow[t]{2}{*}{$\begin{array}{l}\text { Covariate } \\
\text { (As the Dependent Variable in a Bivariate } \\
\text { Linear Regression or Logistic Regression) }\end{array}$} & \multicolumn{2}{|c|}{$\begin{array}{l}\text { Coefficient of Father Absence } \\
\text { (As the Independent Variable in a Bivariate } \\
\text { Linear Regression or Logistic Regression) }\end{array}$} \\
\hline & Before Weighting & After Weighting \\
\hline \multicolumn{3}{|l|}{ Child Demographics } \\
\hline Age & $\begin{array}{l}-0.004 \\
(0.065)\end{array}$ & $\begin{array}{l}-0.023 \\
(0.080)\end{array}$ \\
\hline Gender $($ male $=1$, female $=0)$ & $\begin{array}{c}0.082 \\
(0.113)\end{array}$ & $\begin{array}{c}0.083 \\
(0.139)\end{array}$ \\
\hline \multicolumn{3}{|l|}{ Family Structure } \\
\hline Sibship size & $\begin{array}{c}0.020 \\
(0.043)\end{array}$ & $\begin{array}{l}-0.005 \\
(0.057)\end{array}$ \\
\hline \multicolumn{3}{|l|}{ Child Health } \\
\hline Chronic disease & $\begin{array}{c}0.293 \\
(0.352)\end{array}$ & $\begin{array}{c}0.013 \\
(0.402)\end{array}$ \\
\hline \multicolumn{3}{|l|}{ Child Education } \\
\hline Retention & $\begin{array}{c}0.218 \\
(0.151)\end{array}$ & $\begin{array}{l}-0.187 \\
(0.182)\end{array}$ \\
\hline \multicolumn{3}{|l|}{ Family Economic Capital } \\
\hline Fixed assets and durable goods & $\begin{array}{l}-1.901 * * \\
(0.645)\end{array}$ & $\begin{array}{c}2.255 \\
(2.696)\end{array}$ \\
\hline \multicolumn{3}{|l|}{ Family Cultural Capital } \\
\hline Father's years of education & $\begin{array}{c}0.267 \\
(0.237)\end{array}$ & $\begin{array}{l}-0.173 \\
(0.311)\end{array}$ \\
\hline Mother's years of education & $\begin{array}{l}-0.127 \\
(0.227)\end{array}$ & $\begin{array}{l}-0.161 \\
(0.286)\end{array}$ \\
\hline \multicolumn{3}{|l|}{ Family Social Capital } \\
\hline Neighbor relationship in village & $\begin{array}{l}-0.002 \\
(0.030)\end{array}$ & $\begin{array}{l}-0.018 \\
(0.036)\end{array}$ \\
\hline
\end{tabular}

Note: Robust standard errors in parentheses.

$*<.05, * *<.01, * * *<.001$ 
Table 4 Significant Effect Pathways Linking Father Absence to Educational Attainment in the Full Model

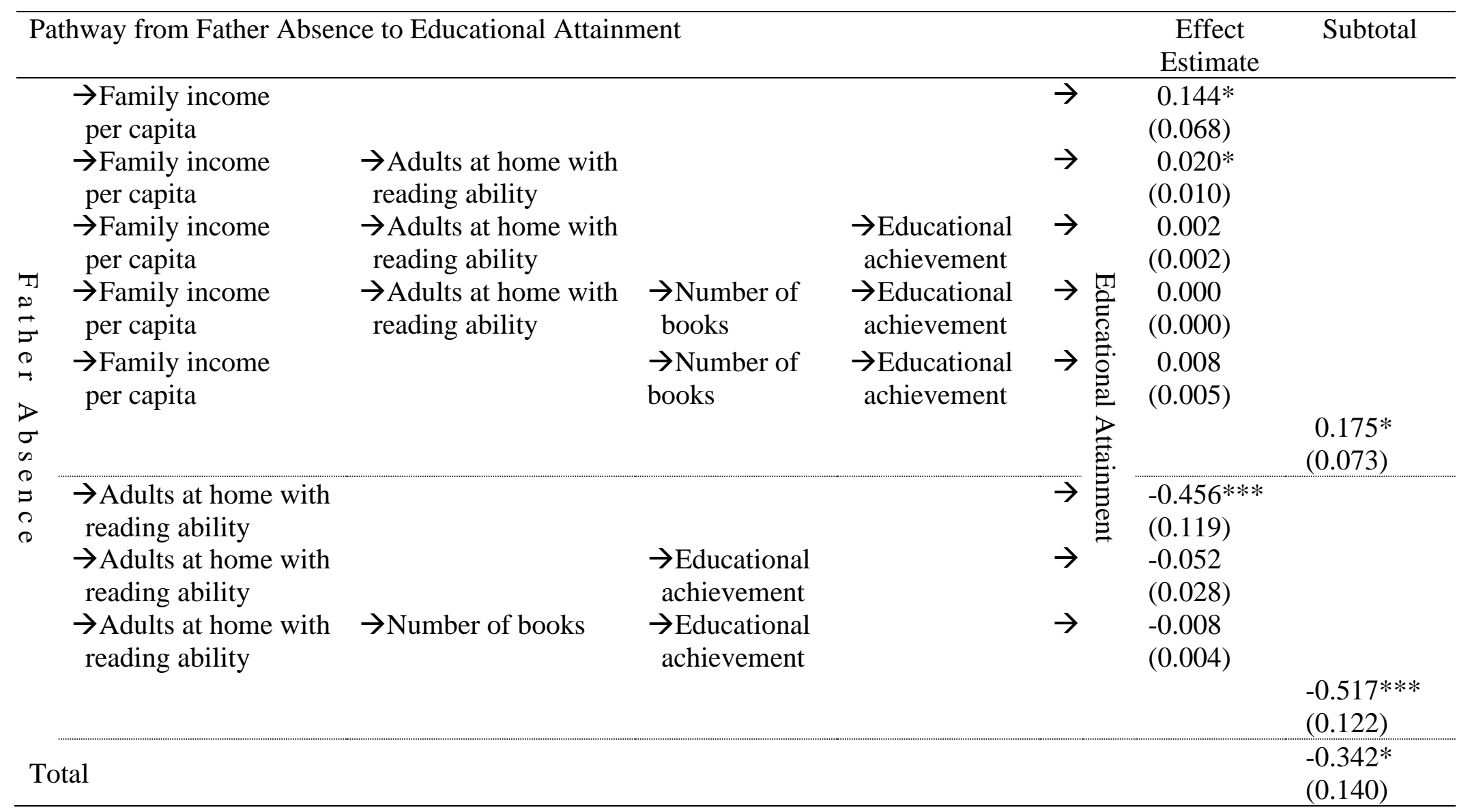

Note: Robust standard errors in parentheses.

$*<.05, * *<.01, * * *<.001$ 
Table 5 Significant Effect Pathways Linking Father Absence to Educational Attainment in Gender-Difference Models

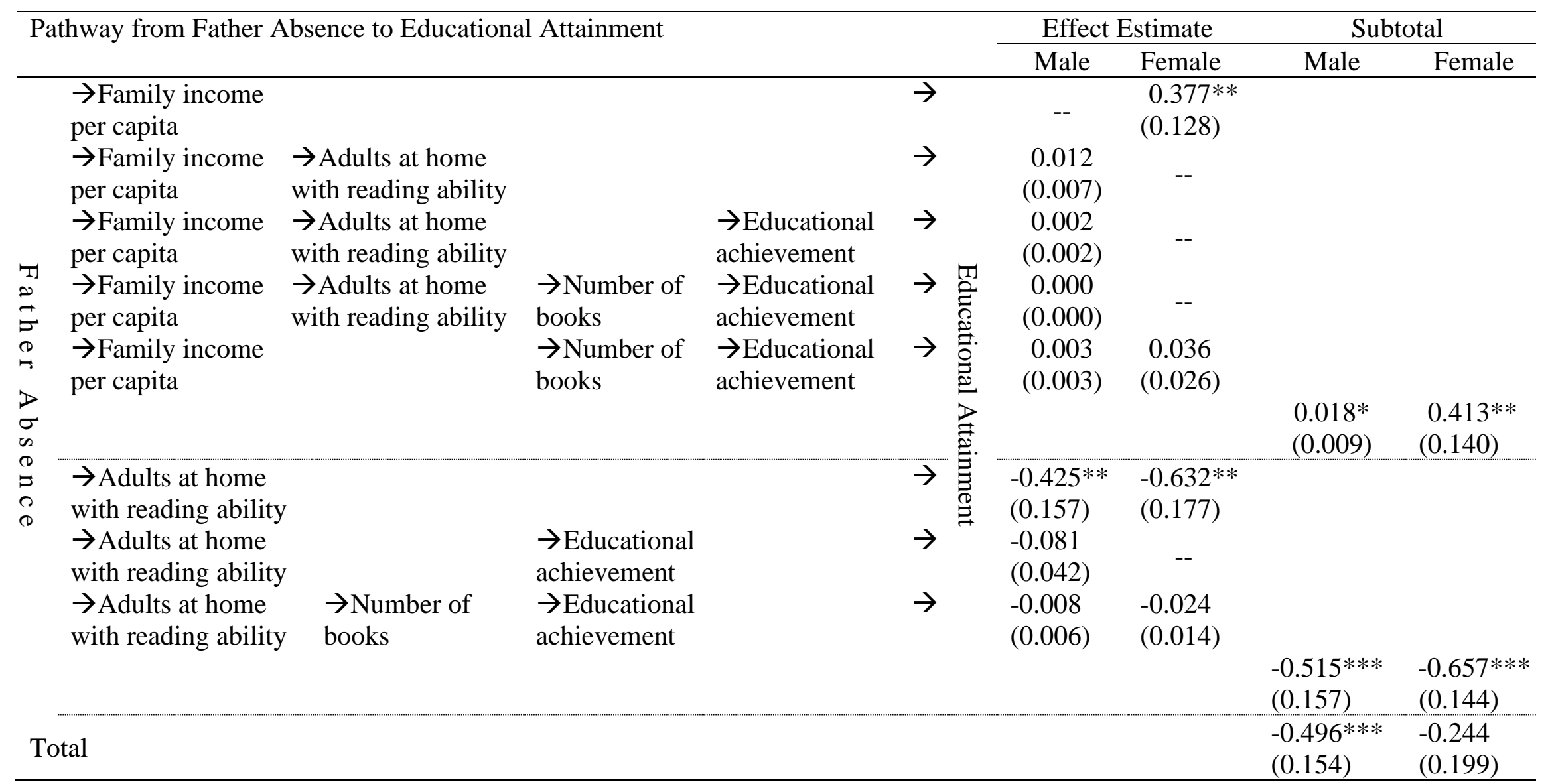

Note: Robust standard errors in parentheses.

$*<.05, * *<.01, * * *<.001$ 
Figure 1 Theoretical Framework

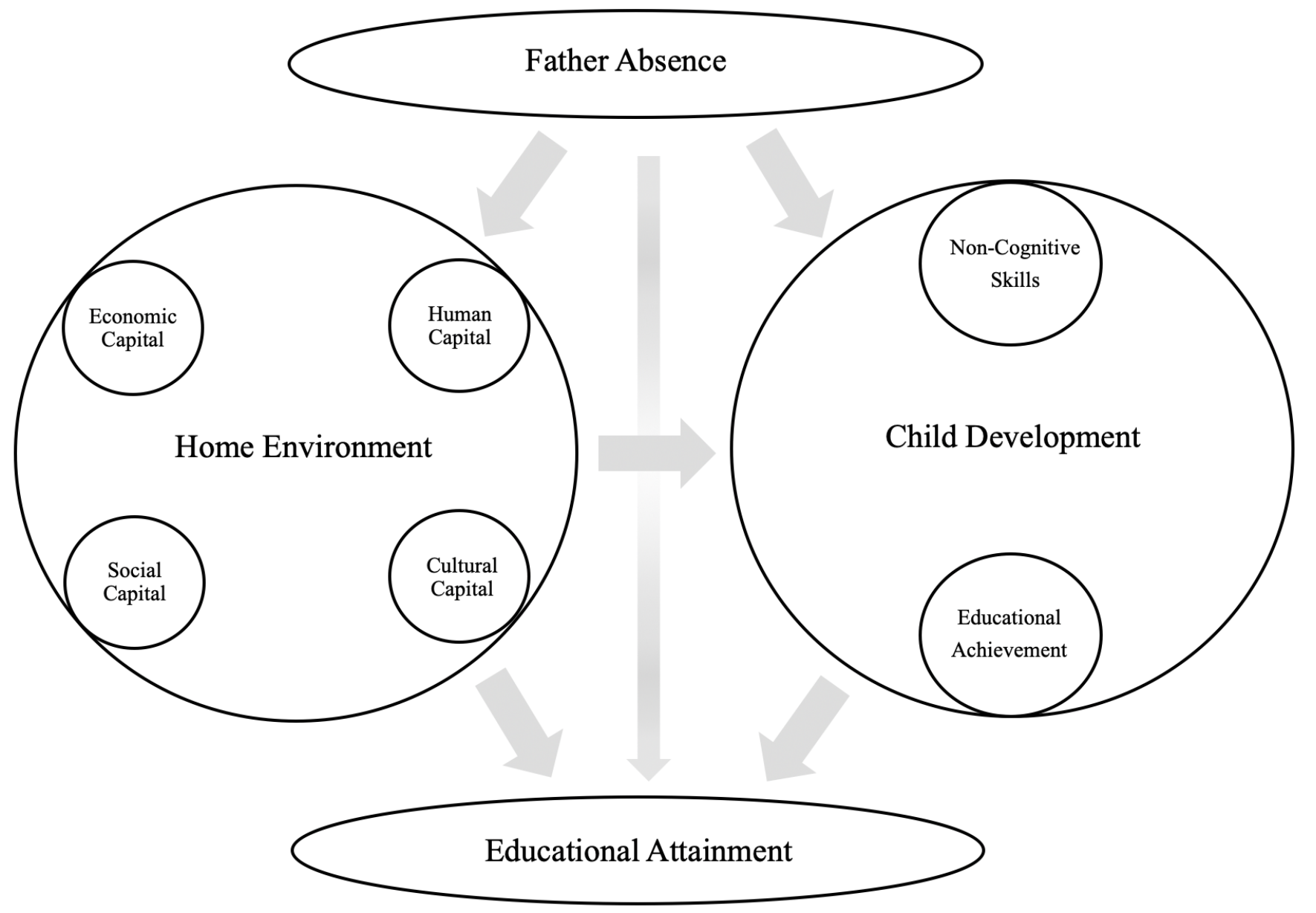


Figure 2 Diagram of the Full Model

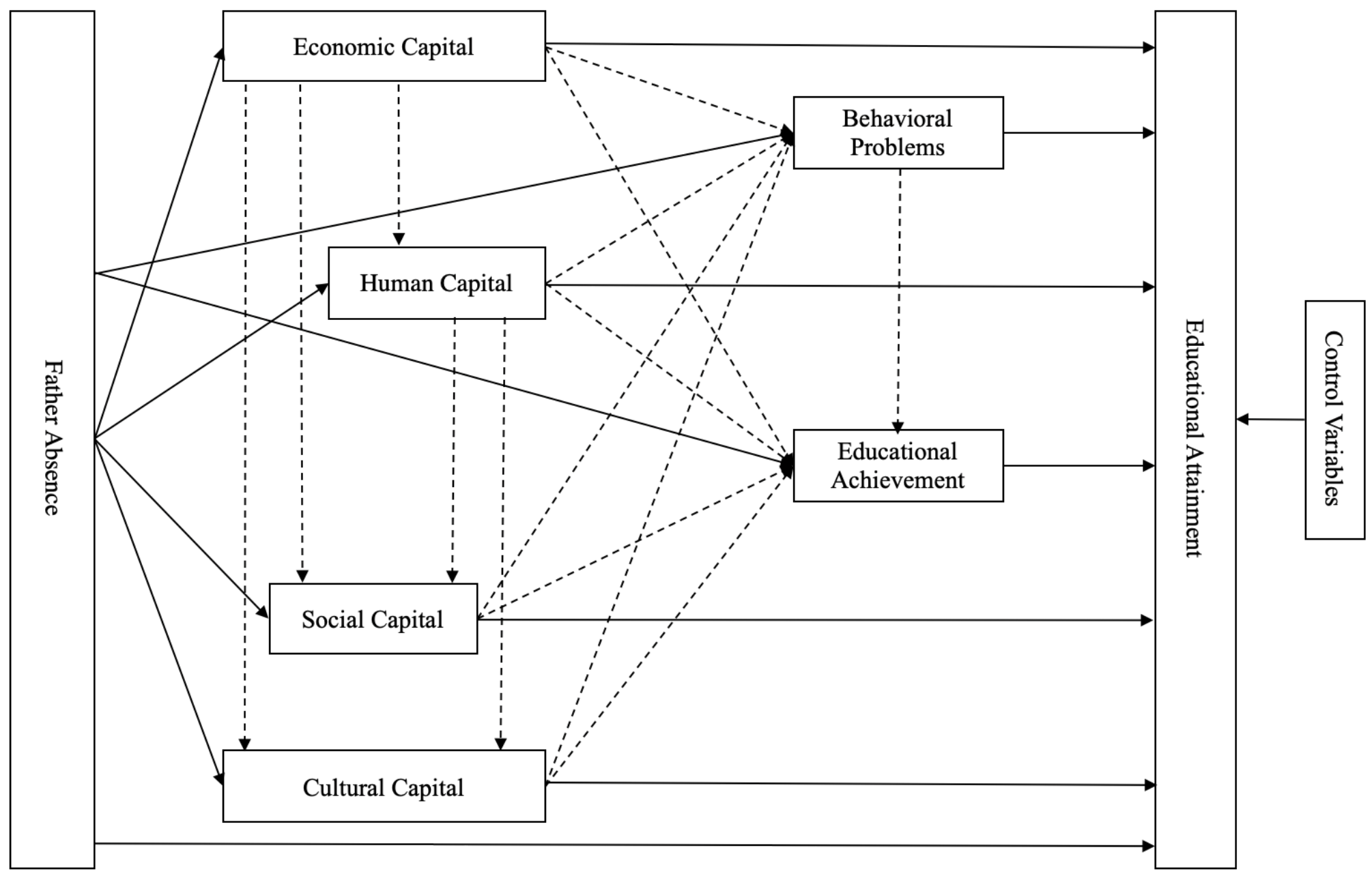

Note: Dashed arrows represent the relationship between different home-environment and child-development mechanisms. 
Figure 3 Significant Effect Pathways in the Full Model

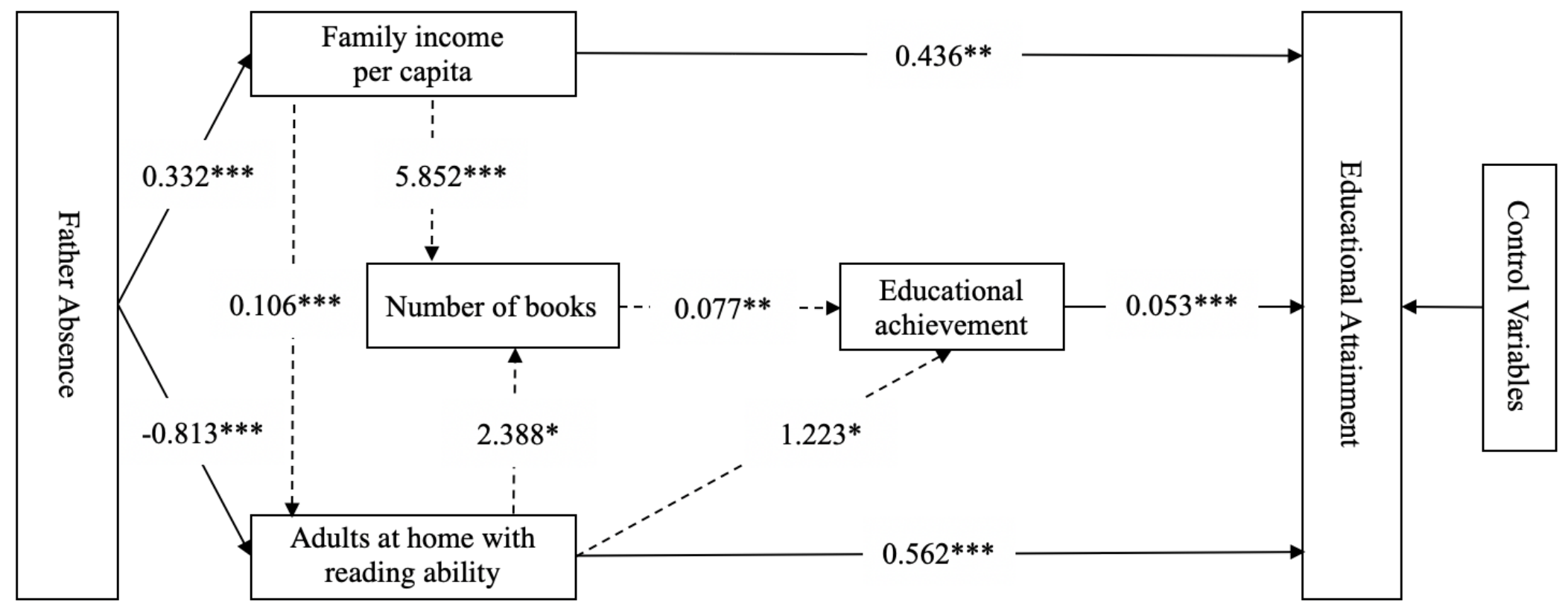

Note: Dashed arrows represent the relationship between different home-environment and child-development mechanisms. Numbers on arrows are unstandardized coefficients.

$*<0.05, * *<0.01, * * *<0.001$ 
Figure 4 Significant Effect Pathways in the Gendered Model

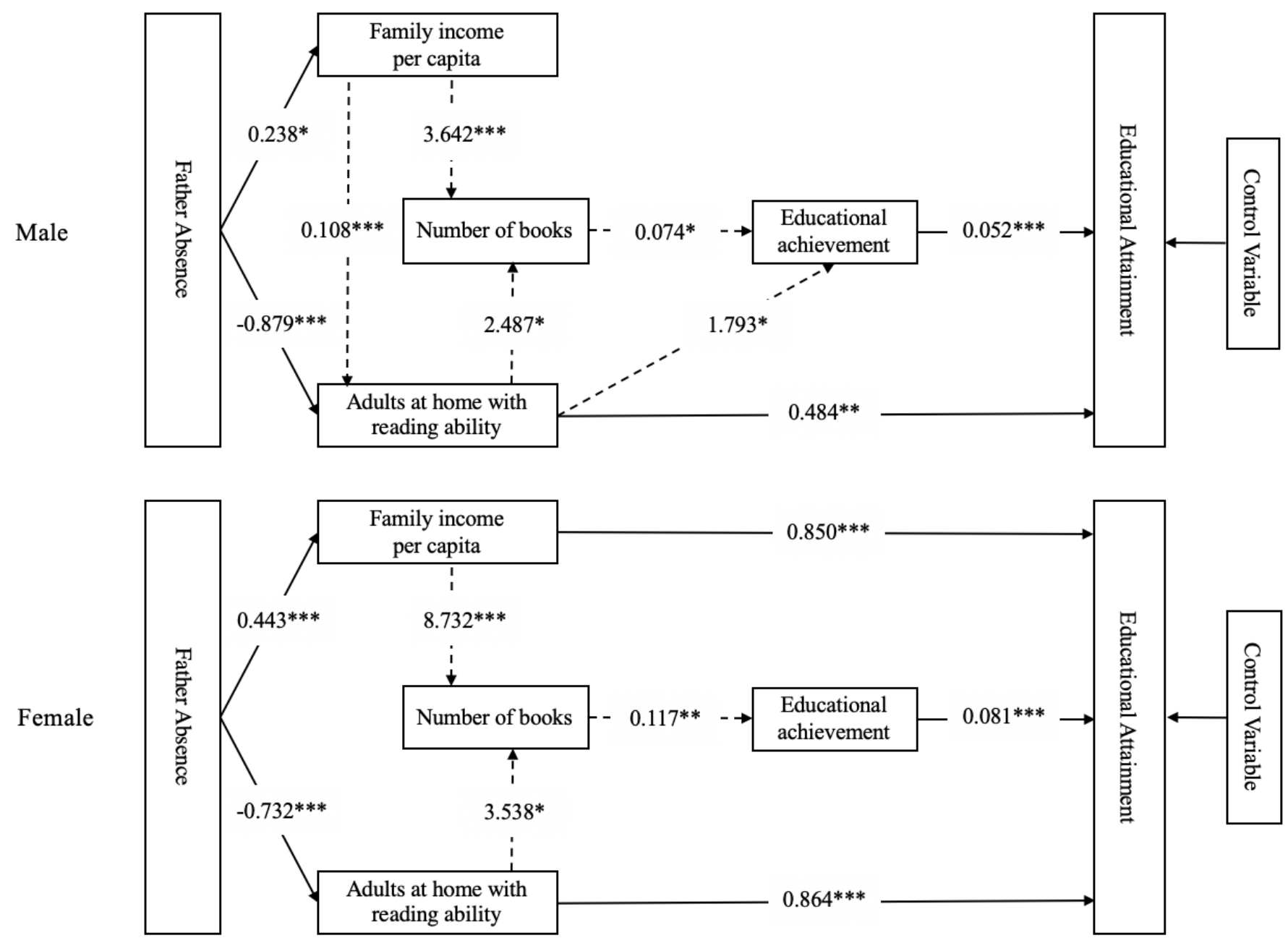

Note: Dashed arrows represent the relationship between different home-environment and child-development mechanisms. Numbers on arrows are unstandardized coefficients.

$*<0.05, * *<0.01, * * *<0.001$ 


\section{Appendix}

Table A1 Weighted Maximum Likelihood Parameter Estimates in the Full Model of Linking Father Absence to Educational Attainment through Different Mechanisms

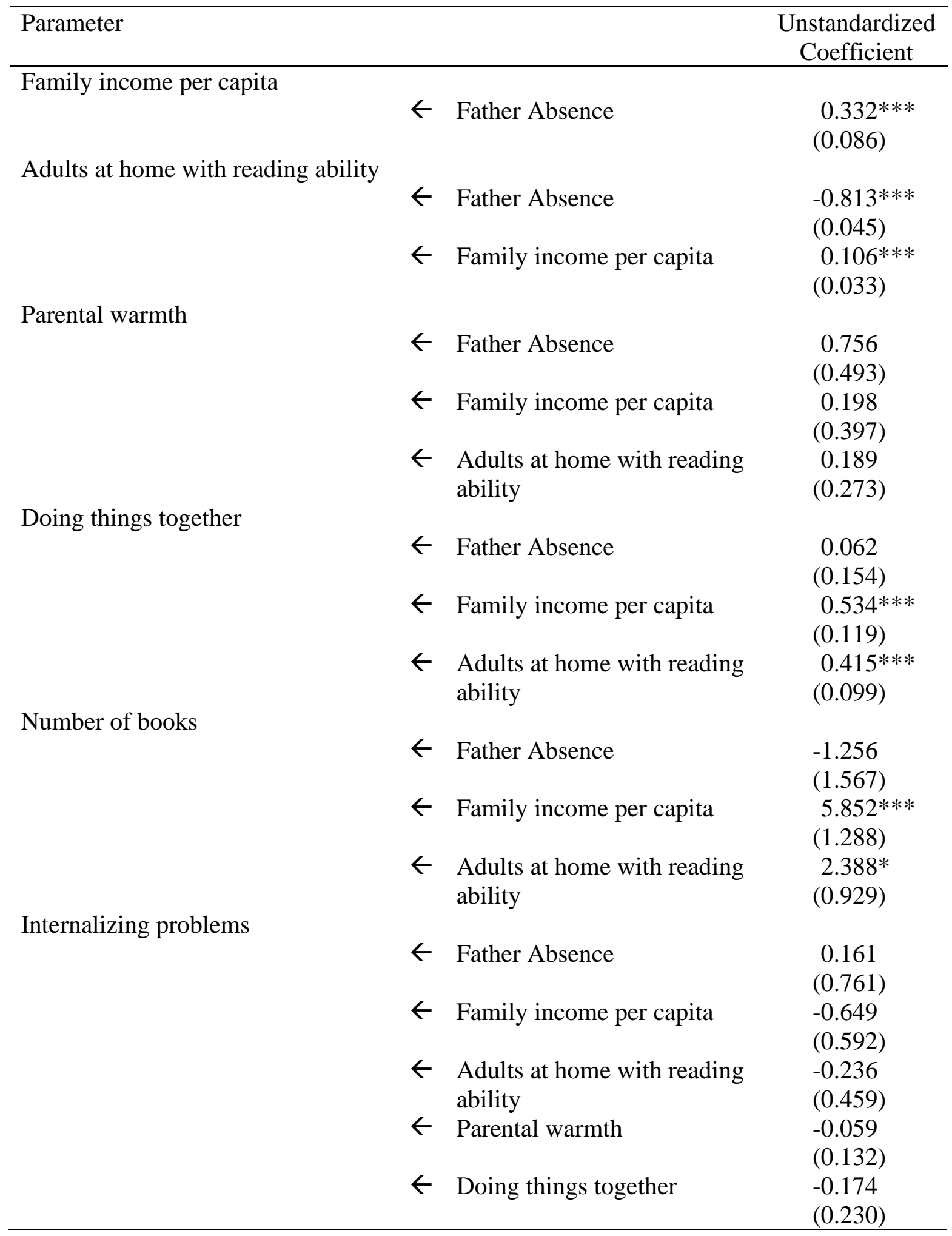




\begin{tabular}{|c|c|c|c|}
\hline & $\leftarrow$ & Number of books & $\begin{array}{l}-0.031 \\
(0.020)\end{array}$ \\
\hline \multicolumn{4}{|l|}{ Externalizing problems } \\
\hline & $\leftarrow$ & Father Absence & $\begin{array}{c}1.080 \\
(0.870)\end{array}$ \\
\hline & $\leftarrow$ & Family income per capita & $\begin{array}{l}-0.763 \\
(0.560)\end{array}$ \\
\hline & $\leftarrow$ & $\begin{array}{l}\text { Adults at home with reading } \\
\text { ability }\end{array}$ & $\begin{array}{l}-0.521 \\
(0.533)\end{array}$ \\
\hline & $\leftarrow$ & Parental warmth & $\begin{array}{l}-0.111 \\
(0.131)\end{array}$ \\
\hline & $\leftarrow$ & Doing things together & $\begin{array}{l}-0.061 \\
(0.229)\end{array}$ \\
\hline & $\leftarrow$ & Number of books & $\begin{array}{l}-0.031 \\
(0.023)\end{array}$ \\
\hline \multicolumn{4}{|l|}{ Educational achievement } \\
\hline & $\leftarrow$ & Father Absence & $\begin{array}{c}0.850 \\
(0.918)\end{array}$ \\
\hline & $\leftarrow$ & Family income per capita & $\begin{array}{c}0.202 \\
(0.871)\end{array}$ \\
\hline & $\leftarrow$ & $\begin{array}{l}\text { Adults at home with reading } \\
\text { ability }\end{array}$ & $\begin{array}{c}1.223^{*} \\
(0.605)\end{array}$ \\
\hline & $\leftarrow$ & Parental warmth & $\begin{array}{c}0.106 \\
(0.129)\end{array}$ \\
\hline & $\leftarrow$ & Doing things together & $\begin{array}{c}0.393 \\
(0.300)\end{array}$ \\
\hline & $\leftarrow$ & Number of books & $\begin{array}{l}0.077 * * \\
(0.025)\end{array}$ \\
\hline & $\leftarrow$ & Internalizing problems & $\begin{array}{c}0.087 \\
(0.147)\end{array}$ \\
\hline & $\leftarrow$ & Externalizing problems & $\begin{array}{l}-0.250 * \\
(0.124)\end{array}$ \\
\hline \multicolumn{4}{|l|}{ Educational Attainment } \\
\hline & $\leftarrow$ & Father Absence & $\begin{array}{c}0.064 \\
(0.241)\end{array}$ \\
\hline & $\leftarrow$ & Family income per capita & $\begin{array}{l}0.436 * * \\
(0.165)\end{array}$ \\
\hline & $\leftarrow$ & $\begin{array}{l}\text { Adults at home with reading } \\
\text { ability }\end{array}$ & $\begin{array}{l}0.562 * * * \\
(0.145)\end{array}$ \\
\hline & $\leftarrow$ & Parental warmth & $\begin{array}{l}0.070 * * \\
(0.025)\end{array}$ \\
\hline & $\leftarrow$ & Doing things together & $\begin{array}{c}0.070 \\
(0.072)\end{array}$ \\
\hline & $\leftarrow$ & Number of books & $\begin{array}{c}0.012 \\
(0.007)\end{array}$ \\
\hline
\end{tabular}




\begin{tabular}{lcc}
\hline & $\leftarrow$ Internalizing problems & 0.005 \\
& $\leftarrow$ Externalizing problems & $(0.034)$ \\
& $\leftarrow$ Educational achievement & -0.031 \\
& & $(0.032)$ \\
& $\leftarrow$ Age & $\left(0.053^{* * *}\right.$ \\
& $\leftarrow$ Gender (male=1, female $=0)$ & -0.052 \\
& & $(0.113)$ \\
& & $0.611^{*}$ \\
Observations & & $2000)$ \\
\hline
\end{tabular}

Note: Robust standard errors in parentheses.

$*<.05, * *<.01, * * *<.001$ 
Table A2 Weighted Maximum Likelihood Parameter Estimates in the Gender-Difference Model of Linking Father Absence to Educational Attainment through Different Mechanisms

Parameter Unstandardized

Coefficient

Family income per capita

Male Female
$\leftarrow$ Father Absence
$0.238 *$
$0.443 * * *$
(0.480)
$(0.132)$

Adults at home with reading ability

\begin{tabular}{|c|c|c|}
\hline$\leftarrow$ Father Absence & $-0.879 * * *$ & $-0.732 * * *$ \\
\hline & $\begin{array}{l}(0.059) \\
0.108 * *\end{array}$ & $\begin{array}{c}(0.069) \\
0.102\end{array}$ \\
\hline eper capita & $(0.038)$ & $(0.052)$ \\
\hline
\end{tabular}

Number of books

Educational achievement

\begin{tabular}{|c|c|c|}
\hline Family income per capita & $\begin{array}{l}3.642 * * * \\
(1.067)\end{array}$ & $\begin{array}{l}8.732 * * * \\
(2.192)\end{array}$ \\
\hline $\begin{array}{l}\text { Adults at home with } \\
\text { reading ability }\end{array}$ & $\begin{array}{l}2.487 * \\
(1.063)\end{array}$ & $\begin{array}{l}3.538 * * \\
(1.347)\end{array}$ \\
\hline
\end{tabular}

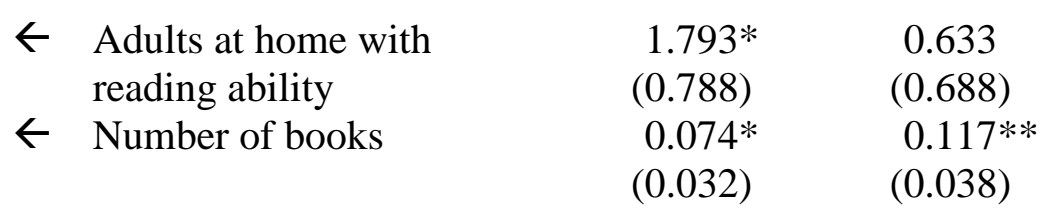

Educational Attainment

$$
\begin{aligned}
& \leftarrow \text { Family income per capita } \\
& \leftarrow \quad \text { Adults at home with } \\
& \leftarrow \text { reading ability } \\
& \leftarrow \text { Educational achievement } \\
&
\end{aligned}
$$$$
0.288
$$$$
(0.221)
$$$$
0.484 * *
$$$$
(0.174)
$$$$
0.052 * * *
$$$$
\text { (0.013) }
$$$$
0.029
$$$$
0.850 * * *
$$$$
(0.228)
$$$$
0.864 * * *
$$$$
\text { (0.189) }
$$$$
0.081 * * *
$$$$
(0.144)
$$$$
(0.013)
$$$$
0.118
$$

1072

Observations

928

Note: Robust standard errors in parentheses.

$*<.05, * *<.01, * * *<.001$ 